\title{
Copper electrodeposition from an acidic plating bath containing accelerating and inhibiting organic additives
}

\author{
M.A. Pasquale*, ${ }^{*}$, L.M. Gassa ${ }^{1}$, A.J. Arvia ${ }^{1}$ \\ Instituto de Investigaciones Fisicoquímicas Teóricas y Aplicadas (INIFTA), Universidad Nacional de La Plata-Consejo Nacional de Investigaciones Científicas y Técnicas, Sucursal 4, \\ Casilla de Correo 16, (1900), La Plata, Argentina
}

\section{A R T I C L E I N F O}

\section{Article history:}

Received 17 December 2007

Received in revised form 24 March 2008

Accepted 29 March 2008

Available online 8 April 2008

\section{Keywords:}

Copper electrodeposition

EIS

Electrodeposit topography

Organic additives

Chloride ions

\begin{abstract}
A B S T R A C T
Copper electrodeposition on copper from still plating solutions of different compositions was investigated utilising electrochemical impedance spectroscopy (EIS), cyclic voltammetry, and scanning electron microscopy (SEM). An acid copper sulphate plating base solution was employed either with or without sodium chloride in the presence of a single additive, either polyethylene glycol (PEG) or 3-mercapto-2propanesulphonic acid (MPSA), and their mixture. Thallium underpotential deposition/anodic stripping was employed to determine the adsorption capability of additives on copper. In the absence of chloride ions, MPSA shows a moderate adsorption on copper, whereas PEG is slightly adsorbed. At low cathodic overpotentials, the simultaneous presence of MPSA and chloride ions accelerates copper electrodeposition through the formation of an MPSA-chloride ion complex in the solution, particularly for about $220 \mu \mathrm{M}$ sodium chloride. The reverse effect occurs in PEG-sodium chloride plating solutions. In this case, from EIS data the formation of a film that interferes with copper electrodeposition can be inferred. At higher cathodic overpotentials, when copper electrodeposition is under mass transport control, the cathode coverage by a PEG-copper chloride-mediated film becomes either partially or completely detached as the concentration of chloride ions at the negatively charged copper surface diminishes. The copper cathode grain topography at the $\mu \mathrm{m}$ scale depends on the cathodic overpotential, plating solution composition and average current density. Available data about the solution constituents and their adsorption on copper make it possible to propose a likely complex mechanism to understand copper electrodeposition from these media, including the accelerating effect of MPSA and the dynamics of PEG-copper chloride complex adsorbate interfering with the surface mobility of depositing copper ad-ions/ad-atoms.
\end{abstract}

(c) 2008 Elsevier Ltd. All rights reserved.

\section{Introduction}

Copper electrodeposition plays a key role in the electronic industry, particularly for printed circuit manufacture and for circuit interconnection where the filling of trenches with a conducting material on the micro- and sub-microscale with a depth/width ratio up to 10 is required [1-3]. Copper chip interconnection technology was developed about two decades ago [4,5], significantly improving the conductance of integrated device connections. For this purpose, copper electrodeposition plating baths utilise a mixture of organic and inorganic additives that obviously increases the complexity of these systems and the reactions occurring there in. Consequently, this fact makes the molecular interpretation of these processes, based upon possible interactions of the growth

\footnotetext{
* Corresponding author. Tel.: +54 221 4257430; fax: +54 2214254642.

E-mail address: miguelp@inifta.unlp.edu.ar (M.A. Pasquale).

1 ISE members.
}

front with the various constituents in the plating solutions, more difficult.

Commonly, the presence of additives in metal plating solutions produces a better levelling effect at the electrodeposit surface as additives distinctly influence the electrodeposition rate at protrusions and recesses [6,7]. Additives may also affect the diffusion of reactants from the bulk of the solution towards the reaction front by changing the plating solution properties, and the surface diffusion of metal ad-ions or ad-atoms to stable lattice sites. Furthermore, the preferential adsorption of either additives or their derivatives on surfaces with diverse curvature may assist the electrodeposition rate [8]. Then, at constant potential, the dominant mechanism of the process might depend both on the plating solution composition, the nature of the additives, and the substrate surface morphology, as concluded from experimental data and Monte Carlo simulations [7,9-13].

Metal electroplating inside trenches can generate deposits with voids, as in the case of subconformal or conformal electrodeposition. In the former case, metal electrodeposition is substantially 
depleted inside trenches, leaving voids in the electrodeposit, whereas for the latter a deposit of equal thickness at all points of the trenches is produced. Conversely, under certain conditions, metal electroplating inside trenches preferentially occurs at the bottom of trenches leading to void-free electrodeposits [5]. This process, usually called "superfilling", involves the simultaneous presence of both small quantities of organic additives under certain concentration ranges and chloride ions to enhance the rate of the electrodeposition process locally. Typical copper plating "superfilling" baths consist of copper sulphate in aqueous sulphuric acid, with the addition of sodium chloride, polyesters such as polyethylene glycol (PEG) or propylene glycol (PPG) as inhibitors, and sulphur-containing molecules, such as 3-mercapto2-propanesulphonic acid (MPSA) as accelerants [4,9].

To study copper electrodeposition from these complex systems, besides electrochemical methods, a large variety of other techniques such as scanning probe microscopy [14-17], quartz crystal microbalance $[17,18]$, surface spectroscopy [19-24] and mass spectrometry [21,25] have been employed.

For copper electrodeposition, the importance of the PEG-chloride ion synergy has been previously reported $[6,7,9,14,15,18,19,24,26-30]$. Similarly, SPS and MPSA are modest inhibitors on their own, whereas the presence of chloride ions accelerates the electrodeposition process $[6,7,9,14-16,19,21,22,31-33]$. Furthermore, it is known that $\mathrm{Cu}(\mathrm{I})$ species are stabilised by complex formation with sulphonic moiety-containing compounds [6,19-21,34-36].

A number of theories have been advanced to explain the mechanism of "superfilling" copper plating. One of them is based upon the curvature-enhanced accelerator coverage [10,11], in which competitive adsorption becomes the main ingredient considered to account for the "superfilling" process. Accordingly, a thiolate-based accelerator displaces the inhibiting PEG complex suppressor from the surface and increases its concentration as the local radius of curvature increases, whereas the PEG complex preferentially adsorbs at the trench entrance inhibiting the lateral growth of the electrodeposit. The concentration of $\mathrm{Cu}(\mathrm{I})$ species would be enhanced inside trenches due to the decrease in the concentration of dissolved oxygen there as compared to planar surfaces [9]. However, most accepted kinetic models assume the preferred adsorption of the accelerant at the bottom of trenches $[7,10]$ and its accumulation there assisted by the simultaneous decrease in surface area caused by metal electrodeposition inside trenches [10]. Other models suggest that the inhibitor, i.e., the large PEG-chloride ion adsorbate, blocks the electrodeposition process at the trench entrance, whereas the smaller accelerant species, i.e., MPSA-chloride complex, reaches the trench bottom producing a bottom-up electrodeposition [15]. Although these theories should be considered important contributions to the mechanism of the above processes, further knowledge about the interaction of intervening species both among them and with the growing copper phase is required.

The main purpose of this work is to contribute to a comprehensive understanding of the role played by additives in copper electrodeposition on copper electrodes in the presence of either single additives or a mixture of additives utilising data from conventional polarisation curves, underpotential deposition (upd)/anodic stripping of thallium on copper, used for the first time for this purpose, scanning electron microscopy (SEM) and electrochemical impedance spectroscopy (EIS). The latter technique, which has been utilised in relation to the system considered in this work in references [37-39] only, becomes attractive to explore further aspects of copper electrodeposition from plating solutions containing a mixture of additives.

\section{Experimental}

\subsection{Electrochemical measurements}

Experiments were carried out in a conventional three-electrode glass electrochemical cell. A large area platinum mesh counter electrode and a saturated sodium sulphate $/ \mathrm{Hg}_{2} \mathrm{SO}_{4} / \mathrm{Hg}(0)$ reference electrode (SSE) were utilised. Working electrodes to be used at rest were prepared from a copper rod (99.99\% purity, $0.4 \mathrm{~cm}$ diameter) set in an inert Teflon ${ }^{\circledR}$ shroud $1.2 \mathrm{~cm}$ in diameter. Each working electrode was polished first with emery paper (1200 grit), and mirror finished using $0.5 \mu \mathrm{m}$ alumina slurry. The influence of the working electrode preparation was studied utilising copper cathodes made by potentiostatic copper electroplating on copper substrates at different potentials $(E)$ and constant charge. For the electrodeposition experiments the copper working electrodes were arranged in the face-down configuration.

The copper plating solutions employed in this work can be distinguished as those made of common constituents, such as water, sulphate/bisulphate anions, protons and copper cations, and those solutions that besides these common constituents also contain additives such as chloride ions, MPSA, PEG (molecular weight 400), and their mixtures at different concentration ratios. The composition of the plating solutions is shown in Table 1. In some cases, for additive-containing solutions, the sodium chloride concentration was varied in the range $0.010 \leq c_{\mathrm{NaCl}} \leq 2.2 \mathrm{mM}$. For each run the plating solution was prepared from reagent grade chemicals and Milli- $\mathrm{Q}^{\circledR}$ water, purged with and kept under nitrogen.

Quasi-steady polarisation curves were run by applying a triangular potential scan at 1,5 and $10 \mathrm{mV} \mathrm{s}^{-1}$ starting from the rest potential $\left(E_{\text {rest }} \approx-0.37 \mathrm{~V}\right.$ ) up to $-0.97 \mathrm{~V}$ (versus SSE) (negative potential excursion) and vice versa (positive potential excursion). The electrochemical impedance spectroscopy measurements were performed in the frequency range $0.001 \leq f \leq 10^{5} \mathrm{~Hz}$, at $E_{\text {rest }}$, as well as at $E=-0.45,-0.50,-0.55,-0.60$ and $-0.65 \mathrm{~V}$ (versus SSE) using a $0.005 \mathrm{~V}$ signal amplitude.

Thallium underpotential deposition/anodic stripping at $v=0.05 \mathrm{~V} \mathrm{~s}^{-1}$ in $1 \mathrm{mM}$ thallium sulphate $+0.5 \mathrm{M}$ sulphuric acid was used as test reaction to investigate the adsorption of additives on copper electrodes at rest. These electrodes consisted of copper wires $0.25 \mathrm{~mm}$ in diameter that were previously mechanically polished with $0.5 \mu \mathrm{m}$ alumina slurry and subsequently electropolished in concentrated phosphoric acid at $1.5 \mathrm{~V}$ for $5 \mathrm{~min}$ [40]. The adsorption of both PEG and MPSA was studied in the range $-0.65 \leq E \leq-0.45 \mathrm{~V}$ (versus SSE), from $0.5 \mathrm{M}$ sulphuric acid $+2.2 \mathrm{mM} \mathrm{NaCl}+880 \mu \mathrm{M}$ PEG and $0.5 \mathrm{M}$ sulphuric acid $+2.2 \mathrm{mM} \mathrm{NaCl}+125 \mu \mathrm{M}$ MPSA aqueous solutions, respectively.

A Zahner IM6d electrochemical workstation for the impedance measurements and a Voltalab 32 (Radiometer Copenhagen) potentiostat for complementary electrochemical experiments were utilised. Runs were performed at room temperature.

Table 1

Composition of copper plating solutions utilised in this work

\begin{tabular}{llllcc}
\hline Solution & $c_{\mathrm{CuSO}_{4}}(\mathrm{M})$ & $c_{\mathrm{H}_{2} \mathrm{SO}_{4}}(\mathrm{M})$ & $c_{\mathrm{NaCl}}(\mathrm{mM})$ & $c_{\mathrm{PEG}}(\mu \mathrm{M})$ & $c_{\mathrm{MPSA}}(\mu \mathrm{M})$ \\
\hline $\mathrm{A}$ & 0.25 & 0.50 & - & - & - \\
$\mathrm{B}$ & 0.25 & 0.50 & 2.20 & - & - \\
$\mathrm{C}$ & 0.25 & 0.50 & 2.20 & 880 & - \\
$\mathrm{D}$ & 0.25 & 0.50 & 2.20 & - & 125 \\
$\mathrm{E}$ & 0.25 & 0.50 & 2.20 & 880 & 125 \\
$\mathrm{~F}$ & 0.25 & 0.50 & - & 880 & - \\
$\mathrm{G}$ & 0.25 & 0.50 & - & - & 125 \\
\hline
\end{tabular}




\subsection{Scanning electron microscopy}

SEM micrographs of copper electrodeposits prepared from different plating solutions were obtained employing a scanning electron microscope (Philips SEM 505). For this purpose electropolished copper sheet cathodes $(1 \mathrm{~cm} \times 1 \mathrm{~cm})$ were used. Their preparation is described further on in Section 3.2. Before the SEM inspection, each electrode was first rinsed with distilled water, and then with analytical grade acetone.

\section{Results}

\subsection{Polarisation curves}

In general, polarisation curves run in the negative potential direction (Fig. 1) show regions with different current/potential functionalities, as expected for a change in the kinetics of the process at different potential, irrespective of the solution composition and potential scanning rate $(v)$. Thus, the polarisation curve from solution A (Fig. 1a), for which the equilibrium potential of the $\mathrm{Cu} / \mathrm{Cu}(\mathrm{II})$ redox couple is $-0.37 \mathrm{~V}$ (versus SSE) at $298 \mathrm{~K}$, shows that from -0.39 up to $-0.50 \mathrm{~V}$ the cathodic process is under activation control, whereas from -0.50 to $-0.65 \mathrm{~V}$ it follows a mixed kinetics, and from $E=-0.65 \mathrm{~V}$ downwards it becomes mass transport-controlled. For solution B (Fig. 1b), in principle, the same description can be considered, except for the current shoulder that appears in the range $-0.39 \geq E \geq-0.53 \mathrm{~V}$. For aqueous $0.25 \mathrm{M}$ copper sulphate, the cathodic limiting current density attained for $E<-0.75 \mathrm{~V}$ is ca. $-16 \mathrm{mAcm}^{-2}$, an almost common figure resulting from all polarisation curves, irrespective of the additive nature and value of $v$. The most remarkable influence of $v$ on the kinetics of the global process appears in the potential range where the polarisation curve exhibits the maximum current density.

For solution F, the polarisation curve (Fig. 1c) becomes similar to that obtained from additive-free solutions as if the addition of $880 \mathrm{mM}$ PEG had no appreciable effect on it. In contrast, the polarisation curve for solution C (Fig. 1d) exhibits a sort of cathodic current plateau in the range $-0.55<E<-0.45 \mathrm{~V}$, irrespective of $v$.

For solution $\mathrm{G}$ (Fig. 1e), the polarisation curve shows a small shoulder in the range $-0.45<E<-0.55 \mathrm{~V}$. The higher $v$, the more noticeable the shoulder and the smaller the potential at which the shoulder appears. In this case, the rate of copper electrodeposition increases in the range $-0.45<E<-0.55 \mathrm{~V}$, presumably because of the fast electroreduction of a $\mathrm{Cu}(\mathrm{I})-\mathrm{MPSA}$ complex $[9,10]$. Furthermore, the possible adsorption of MPSA can be inferred from the decreasing slope of the current density versus $E$ plot at $E<-0.55 \mathrm{~V}$. For solution D (Fig. 1f), the shoulder in the polarisation curve is enhanced and the current density maximum is shifted positively. Then, at constant sodium chloride concentration $\left(c_{\mathrm{NaCl}}=2.2 \mathrm{mM}\right)$ both MPSA and chloride ions make copper electrodeposition at constant $E$ faster.

Polarisation curves in the backward direction show the disappearance of the cathodic current shoulder found in the preceding scan and a hysteresis loop that is significantly smaller for chloride-containing solutions, irrespective of their composition. The presence of chloride ions in the plating solution makes the electrochemical reaction process more reversible at lower potentials.

\subsection{Electrochemical impedance spectroscopy data}

EIS data depend on both $E$ and the plating solution composition. Nyquist plots from solutions B-E run at $E=-0.45 \mathrm{~V}$ (Fig. 2) show a first rather depressed semicircle in the high frequency range and a very small, flat and poorly defined time constant in the medium frequency range. Data from all solutions approach a short straightline portion in the Nyquist plot at $f \leq 0.1 \mathrm{~Hz}$, although at the lowest values of $f$ data scattering is observed. The impedance value associated with the first time constant decreases in the order: solution $\mathrm{C}>\mathrm{E}>\mathrm{B}>\mathrm{D}$.

Nyquist plots from solutions $\mathrm{B}, \mathrm{D}$ and $\mathrm{E}$ at $E=-0.55 \mathrm{~V}$ (Fig. 2) exhibit a single well-defined semicircle in the high $f$-range followed by a straight line approaching a Warburg-type diffusion behaviour at intermediate values of $f$. At the same value of $E$, the Nyquist plot from solution $C$ displays an inductive loop for $f<0.1 \mathrm{~Hz}$ (Fig. 2). Data scattering at low $f$ is not surprising as copper electrodeposition itself implies a considerable change in the active cathode surface area, as concluded from the SEM micrographs described further on in Section 3.4. At this potential, the impedance values associated with the first time constant are larger for data from solution C, although this difference is smaller than that reported above.

The Nyquist plots from solutions $\mathrm{B}, \mathrm{D}$ and $\mathrm{E}$ at $E=-0.60 \mathrm{~V}$ as well as those from all other plating solutions at $E=-0.65 \mathrm{~V}$ (Fig. 3) essentially exhibit the same features described above for $E=-0.55 \mathrm{~V}$, except for solution C. For solutions A, D and E at $E=-0.60 \mathrm{~V}$, Nyquist plots display a single well-defined semicircle at high $f$ and a Warburg-type diffusion in the range $100<f<1 \mathrm{~Hz}$. The occurrence of this diffusion process is consistent with the appearance of the limiting cathodic current in the polarisation curves. Only the Nyquist plot from solution $C$ in the range $251 \leq f \leq 1 \mathrm{~Hz}$ shows an intermediate flat curve that is equivalent to a one quarter of a circle. For $E=-0.60$ and $-0.65 \mathrm{~V}$ and at high values of $f$, almost the same time constant for all plating solutions is found.

Following previous work [41], the linear Warburg-type contribution appearing in the middle $f$-range of the Nyquist plot for solution $\mathrm{D}$ at $E=-0.45 \mathrm{~V}$ and for all solutions at $E<-0.55 \mathrm{~V}$, except for solution C (Figs. 2 and 3), although not exhibiting the theoretical slope of $45^{\circ}$, was confirmed by running EIS experiments in a rotating copper disc at $\omega=1500 \mathrm{rpm}$.

EIS data for $E=-0.45 \mathrm{~V}$ can be fitted by the equivalent circuit depicted in Fig. 4a, where $R_{\mathrm{S}}$ is the resistance of the solution; $C_{\mathrm{dl}}$ is the capacitance of the electrical double layer; and $R_{\mathrm{ct}}$ is the copper ion reduction charge transfer resistance. The capacitance in the circuit is supported by the parameter $\alpha$ close to 1 . This parameter describes the width of the relaxation times in the frequency space and it is related to the constant phase element used to fit the data. The second time constant is assigned to adsorbate formation from chloride-containing species, such as PEG + chloride ion, and MPSA + chloride ion species. A second constant phase element can be used to simulate data for the medium frequency range. Particularly for solutions containing PEG, capacity values of the order of $1 \mathrm{mF} \mathrm{cm}^{-2}$, which are consistent with a film formation at the cathode, are obtained. Unfortunately, no reliable conclusions can be derived from the non-stationary response of EIS data at low frequency. This fact is probably due to the continued renewal of the cathode surface during the process and further complications arising when PEG-containing solutions are employed, as referred to further on.

Data processing from solutions B, D and $\mathrm{E}$ at $E=-0.55 \mathrm{~V}$ (Fig. 2), and from all solutions at $E=-0.60$ and $-0.65 \mathrm{~V}$, was performed with an equivalent circuit consisting of a resistance $\left(R_{\mathrm{S}}\right)$ connected in series to a capacitance $\left(C_{\mathrm{dl}}\right)$-resistance $\left(R_{\mathrm{ct}}\right)$ parallel arrangement and a Warburg element $(W)$ (Fig. 4b). Parameters derived from impedance data and components of the equivalent circuit are shown in Table 2. For solutions B, D and E the overall cathodic process becomes faster than for solution $C$. For the latter, the inductive loop at $f<0.1 \mathrm{~Hz}$ can be explained by the detachment of a "PEG + chloride ion" adsorbed film $[42,43]$. 

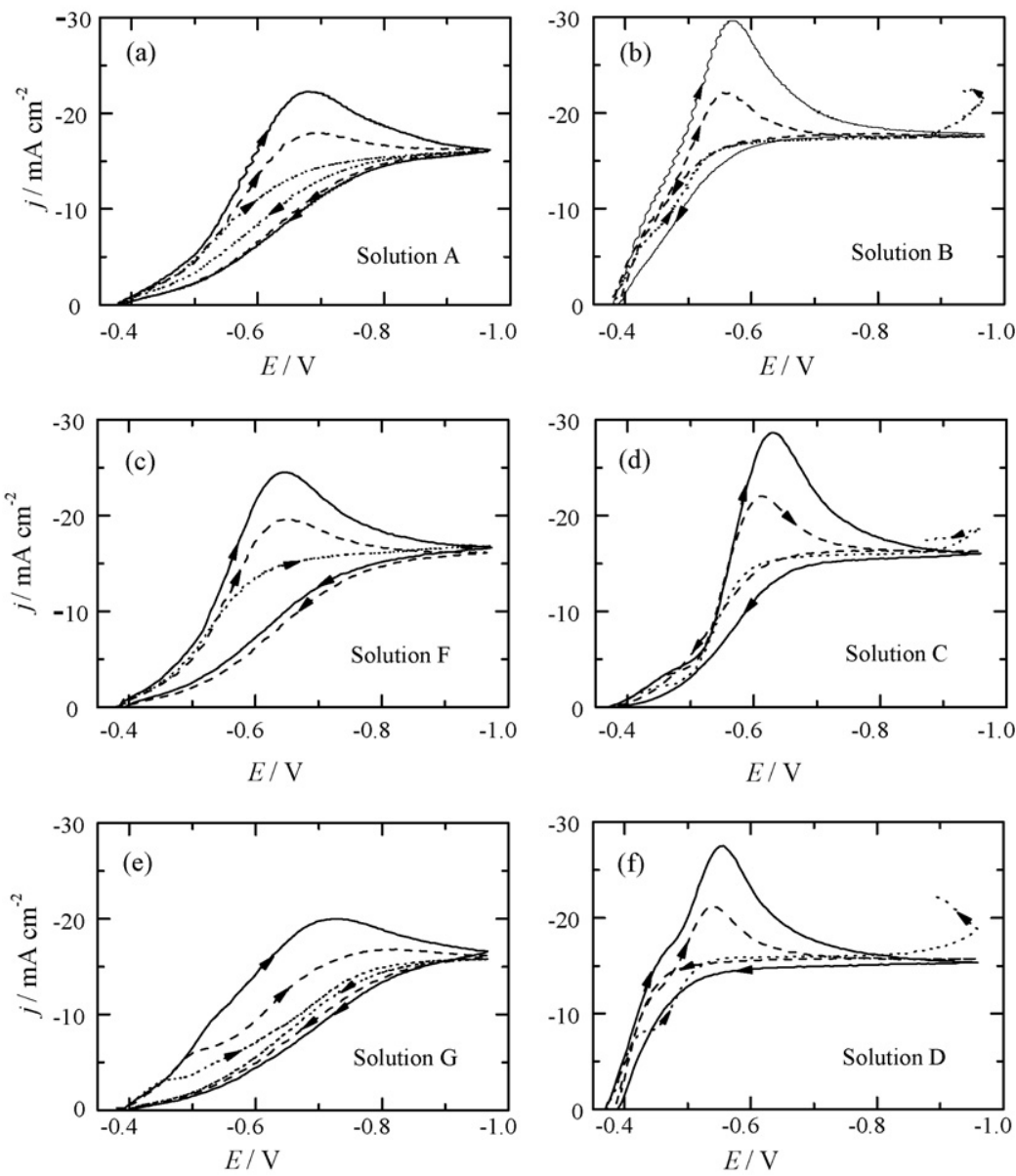

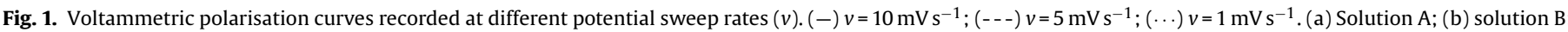
(c) solution F; (d) solution C; (e) solution G; (f) solution D. T=298 K.

Typical Bode plots for solution $C$ at $E=-0.45 \mathrm{~V}$ (Fig. 5a) and solution $C$ at $E=-0.65 \mathrm{~V}$ (Fig. 5b) show a good agreement between experimental and fitting data.

The consistency of EIS data at constant $E$ and different solution composition was checked by the reconstruction of the polarisation curves (Fig. 6) utilising the apparent station- ary cathodic current density $\left(j_{\text {css }}\right)$ determined from current transients run simultaneously with EIS data (Table 2). The reconstructed polarisation curves exhibit the same general behaviour as those depicted in Fig. 1. As is expected, at constant potentials, for all plating solutions the values of $j_{\text {css }}$ are close to those read from the polarisation curve run in the

Table 2

Parameters used for fitting the EIS data in Figs. 2 and 3

\begin{tabular}{|c|c|c|c|c|c|c|c|}
\hline Solution & $j_{\mathrm{css}}\left(\mathrm{mAcm}^{-2}\right)$ & $R_{\mathrm{S}}\left(\Omega \mathrm{cm}^{2}\right)$ & $C_{\mathrm{dl}}\left(\mu \mathrm{Fcm}^{-2}\right)$ & $\alpha$ & $R_{\mathrm{ct}}\left(\Omega \mathrm{cm}^{2}\right)$ & $C_{\mathrm{ad}}\left(\mu \mathrm{Fcm}^{-2}\right)$ & $R_{1}\left(\Omega \mathrm{cm}^{2}\right)$ \\
\hline \multicolumn{8}{|c|}{$E=-0.45 \mathrm{~V}$ (versus SSE) } \\
\hline B & 4.1 & 0.56 & 10.2 & 0.90 & 3.63 & 816 & 3.01 \\
\hline C & 0.6 & 0.39 & 21.3 & 0.99 & 21.6 & 1133 & 27.0 \\
\hline $\mathrm{D}$ & 6.5 & 0.86 & 35.6 & 0.99 & 2.50 & 717 & 1.95 \\
\hline $\mathrm{E}$ & 4.0 & 0.54 & 50.5 & 0.96 & 1.93 & 1185 & 5.80 \\
\hline Solution & $j_{\mathrm{css}}\left(\mathrm{mAcm}^{-2}\right)$ & $R_{\mathrm{s}}\left(\Omega \mathrm{cm}^{2}\right)$ & & $C_{\mathrm{dl}}\left(\mu \mathrm{Fcm}^{-2}\right)$ & $\alpha$ & $R_{\mathrm{ct}}\left(\Omega \mathrm{cm}^{2}\right)$ & $l_{\mathrm{D}}(\mathrm{cm})$ \\
\hline \multicolumn{8}{|c|}{$E=-0.55 \mathrm{~V}($ versus SSE) } \\
\hline B & 12.1 & 0.58 & & 30.0 & 0.95 & 3.25 & 0.0022 \\
\hline $\mathrm{C}$ & 4.8 & 0.78 & & 21.0 & 0.95 & 7.14 & - \\
\hline $\mathrm{D}$ & 16.2 & 1.12 & & 28.7 & 0.95 & 2.87 & 0.0023 \\
\hline E & 14.3 & 0.81 & & 37.0 & 0.92 & 2.38 & 0.0011 \\
\hline Solution & $j_{\mathrm{css}}\left(\mathrm{mAcm}^{-2}\right)$ & $R_{\mathrm{S}}\left(\Omega \mathrm{cm}^{2}\right)$ & & $C_{\mathrm{dl}}\left(\mu \mathrm{Fcm}^{-2}\right)$ & $\alpha$ & $R_{\mathrm{ct}}\left(\Omega \mathrm{cm}^{2}\right)$ & $l_{\mathrm{D}}(\mathrm{cm})$ \\
\hline \multicolumn{8}{|c|}{$E=-0.65 \mathrm{~V}$ (versus SSE) } \\
\hline B & 16.2 & 0.61 & & 17.0 & 0.95 & 2.45 & 0.0022 \\
\hline $\mathrm{C}$ & 15.2 & 0.62 & & 26.0 & 0.95 & 2.46 & 0.0040 \\
\hline $\mathrm{D}$ & 19.0 & 1.05 & & 27.0 & 0.95 & 2.24 & 0.0021 \\
\hline $\mathrm{E}$ & 23.8 & 1.05 & & 27.1 & 0.92 & 2.05 & 0.0021 \\
\hline
\end{tabular}


$-0.45 \mathrm{~V}$

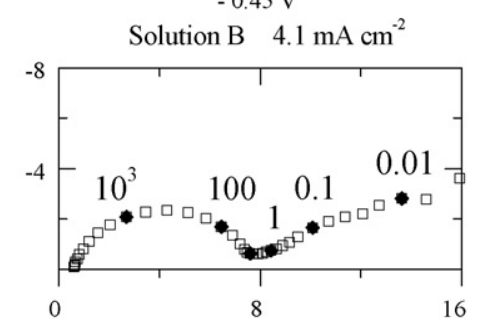

Solution $\mathrm{C} 0.6 \mathrm{~mA} \mathrm{~cm}^{-2}$

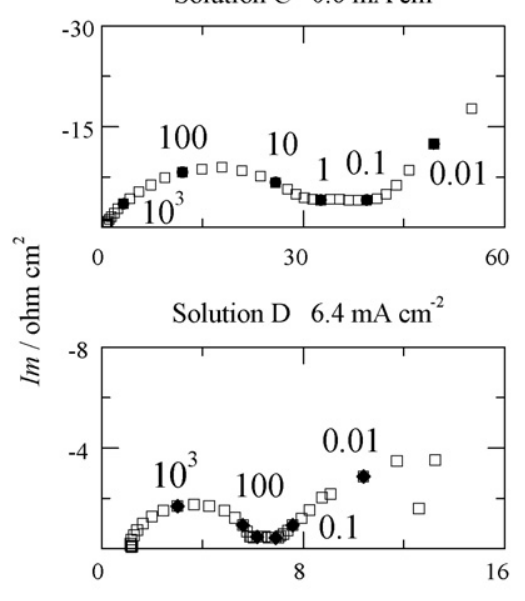

Solution E $4.0 \mathrm{~mA} \mathrm{~cm}^{-2}$

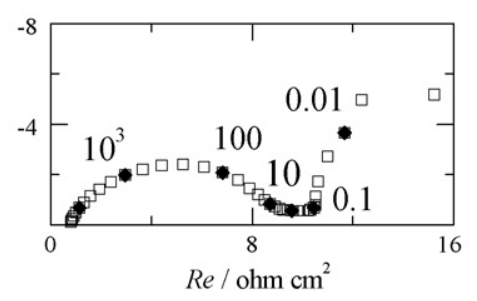

$-0.55 \mathrm{~V}$

Solution B $12.1 \mathrm{~mA} \mathrm{~cm}^{-2}$
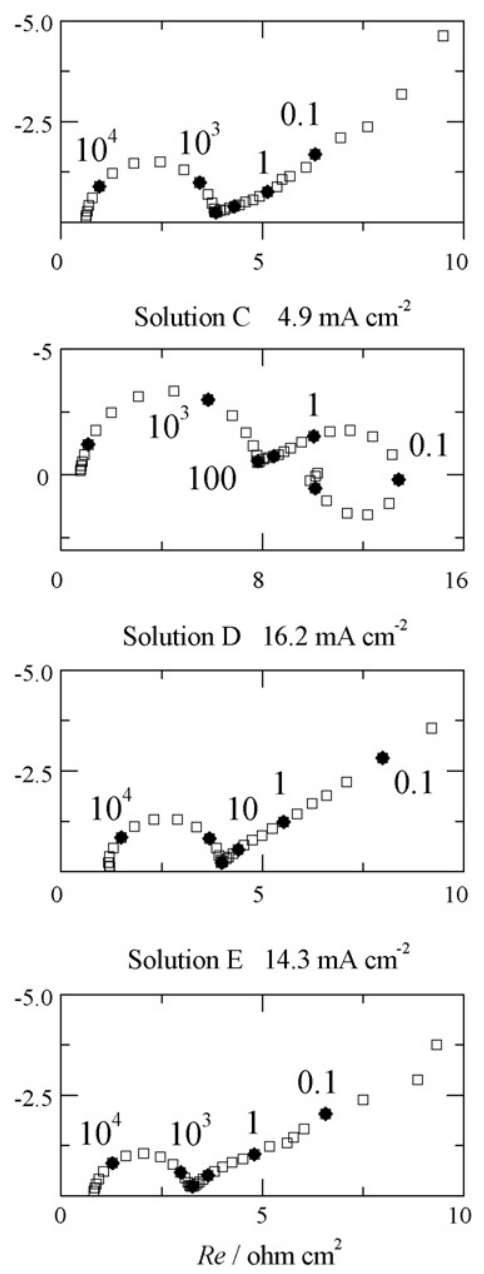

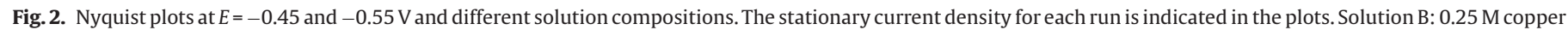

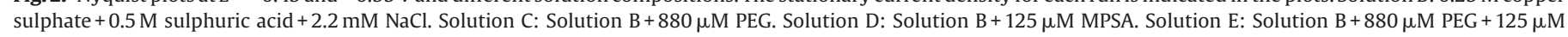
MPSA. Frequency values in the plots correspond to full dots. $T=298 \mathrm{~K}$.

reverse direction. Values of $j_{\text {css }}$ increase in the order: solution $\mathrm{D} \approx \mathrm{E}>\mathrm{B}>\mathrm{C}$.

\subsubsection{Influence of copper cathode preparation}

EIS data from solutions $\mathrm{B}-\mathrm{E}$ at $E=-0.55 \mathrm{~V}$ were also obtained utilising copper samples electroplated at either $E=-0.45 \mathrm{~V}$ (experiment 2) or $E=-0.65 \mathrm{~V}$ (experiment 3 ) for $40 \mathrm{~min}$ to be compared to data resulting from fresh polished copper cathodes (experiment 1 ) (Table 3). In this case, the resulting morphology will depend on both $E$ and $j_{\text {css }}$.

The Nyquist plots at $E=-0.55 \mathrm{~V}$ from solutions B-E are similar to those described in Section 3.2. Consequently, data simulation was made employing the equivalent circuit depicted in Fig. 4b. The respective fitting parameters and $j_{\text {css }}$ values are assembled in Table 3. The variation of $j_{\mathrm{css}}$ with the composition of the plating solution shows the same trend as that of the extension of the impedance loop at high frequency. The difference in data from solutions $\mathrm{D}$ and $\mathrm{E}$ is attributed to the relatively large increase in the cathode active surface area resulting from solution E, as inferred from the comparison of SEM micrographs (Section 3.4).

For solutions B, D and E, the value of $R_{\mathrm{ct}}$ decreases from experiment 1 to 3 , a fact that can be assigned to the increase in the cathode active surface area. Conversely, for solution $C$ experiment
2 shows an increase in $R_{\mathrm{ct}}$ that can be related to a hindrance of copper electrodeposition caused by the partial blockage of the cathode by a PEG-chloride-mediated complex film as the process at $E=-0.45 \mathrm{~V}$ becomes sufficiently slow to permit the adsorption of a PEG-chloride-mediated complex. On the other hand, experiment 3 implies the relatively fast renewal of the cathode surface by copper electrodeposition at $E=-0.65 \mathrm{~V}$. This fact is consistent with the small value of $R_{\mathrm{ct}}$ that occurs when the blocking capability of PEG-chloride-mediated complex adsorption is exceeded.

For solutions $B$ and $D$, the calculated diffusion length of the diffusing species through the blocking layer $l_{\mathrm{D}}$ (Table 3 ), considering the upper limiting value of the diffusion coefficient of the species $D_{\mathrm{s}}=6 \times 10^{-6} \mathrm{~cm}^{2} \mathrm{~s}^{-1}$, increases from experiment 1 to 3 , whereas for solution $E$ the value of $l_{D}$ remains almost constant despite the increase in surface roughness.

Nyquist plots at $E=-0.55 \mathrm{~V}$ utilising an electrodeposited copper cathode from solution $\mathrm{D}$ at $E=-0.65 \mathrm{~V}$ display a $45^{\circ}$ straight-line Warburg diffusion much better defined than that for polished copper (Fig. 2). This fact suggests that in the absence of PEG, the efficiency of MPSA + chloride ion-containing accelerant increases with the number density of active protrusions that appears at the electrodeposited copper. In agreement with the morphology and roughness of the electrodeposits, as described further on, these 
$-0.60 \mathrm{~V}$

Solution B $-16.6 \mathrm{~mA} \mathrm{~cm}^{-2}$
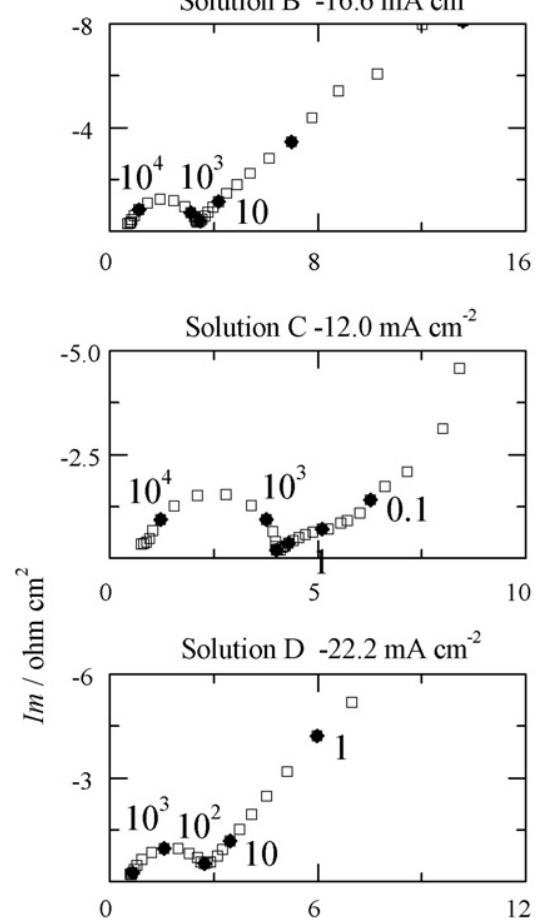

Solution E $-18.0 \mathrm{~mA} \mathrm{~cm}^{-2}$

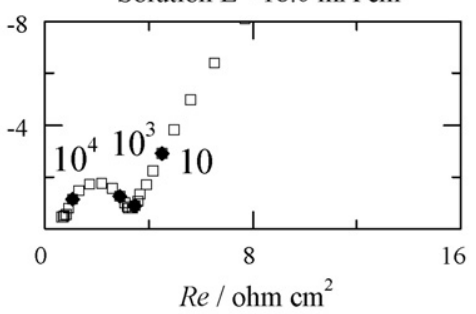

$-0.65 \mathrm{~V}$

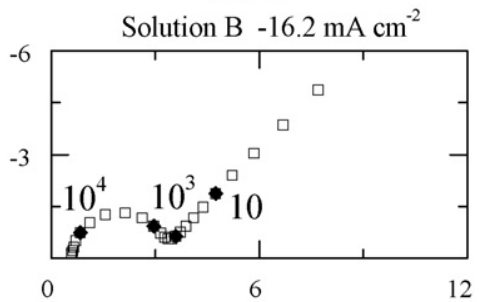

12
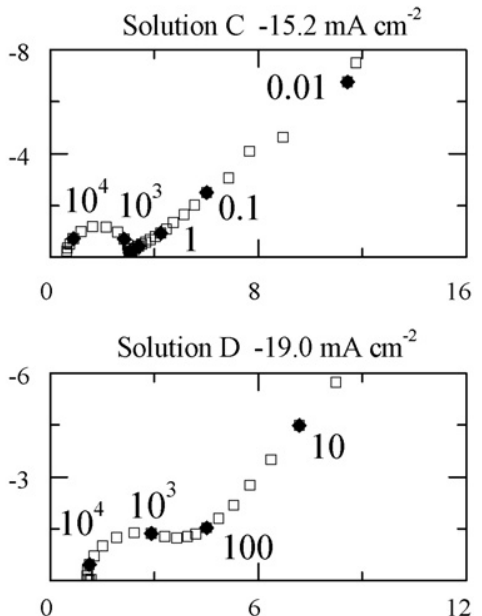

0

Solution E $-23.8 \mathrm{~mA} \mathrm{~cm}^{-2}$

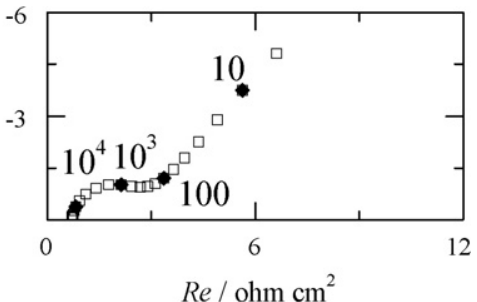

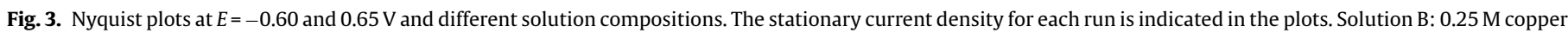

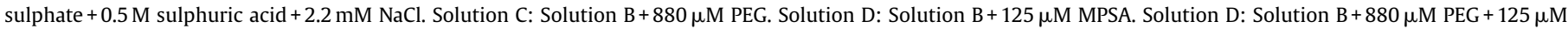
MPSA. Frequency values in the plots correspond to full dots. $T=298 \mathrm{~K}$.

Table 3

Parameters used for fitting EIS data from copper electrodes with different pre-treatments

\begin{tabular}{|c|c|c|c|c|c|c|}
\hline No. & $j_{\mathrm{css}}\left(\mathrm{mAcm}^{-2}\right)$ & $R_{\mathrm{S}}\left(\Omega \mathrm{cm}^{2}\right)$ & $C_{\mathrm{dl}}\left(\mu \mathrm{Fcm}^{-2}\right)$ & $\alpha$ & $R_{\mathrm{ct}}\left(\Omega \mathrm{cm}^{2}\right)$ & $l_{\mathrm{D}}(\mathrm{cm})$ \\
\hline \multicolumn{7}{|c|}{ Solution $\mathrm{B} ; E=-0.55 \mathrm{~V}$} \\
\hline 1 & 12.1 & 0.62 & 26.7 & 0.95 & 3.25 & 0.0022 \\
\hline 2 & 13.7 & 0.62 & 20.1 & 0.99 & 3.14 & 0.0028 \\
\hline 3 & 14.1 & 0.59 & 34.4 & 0.99 & 2.65 & 0.0049 \\
\hline \multicolumn{7}{|c|}{ Solution C; $E=-0.55 \mathrm{~V}$} \\
\hline 1 & 4.8 & 0.78 & 20.4 & 0.95 & 7.14 & - \\
\hline 2 & 4.4 & 0.61 & 18.3 & 0.97 & 8.21 & - \\
\hline 3 & 5.2 & 0.60 & 20.8 & 0.97 & 6.36 & - \\
\hline \multicolumn{7}{|c|}{ Solution $\mathrm{D} ; E=-0.55 \mathrm{~V}$} \\
\hline 1 & 14.3 & 1.12 & 28.7 & 0.95 & 2.87 & 0.0023 \\
\hline 2 & 16.5 & 1.05 & 22.6 & 0.99 & 2.41 & 0.0096 \\
\hline 3 & 19.0 & 1.04 & 50.1 & 0.99 & 2.07 & 0.0042 \\
\hline \multicolumn{7}{|c|}{ Solution $\mathrm{E} ; E=-0.55 \mathrm{~V}$} \\
\hline 1 & 16.0 & 0.81 & 36.8 & 0.92 & 2.38 & 0.0011 \\
\hline 2 & 19.2 & 0.78 & 28.3 & 0.97 & 2.03 & 0.0017 \\
\hline 3 & 24.5 & 0.70 & 197 & 0.92 & 1.62 & 0.0017 \\
\hline
\end{tabular}

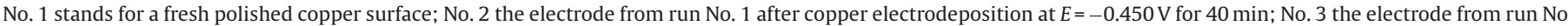
2 after further copper electrodeposition at $E=-0.650 \mathrm{~V}$ for another $40 \mathrm{~min}$. 

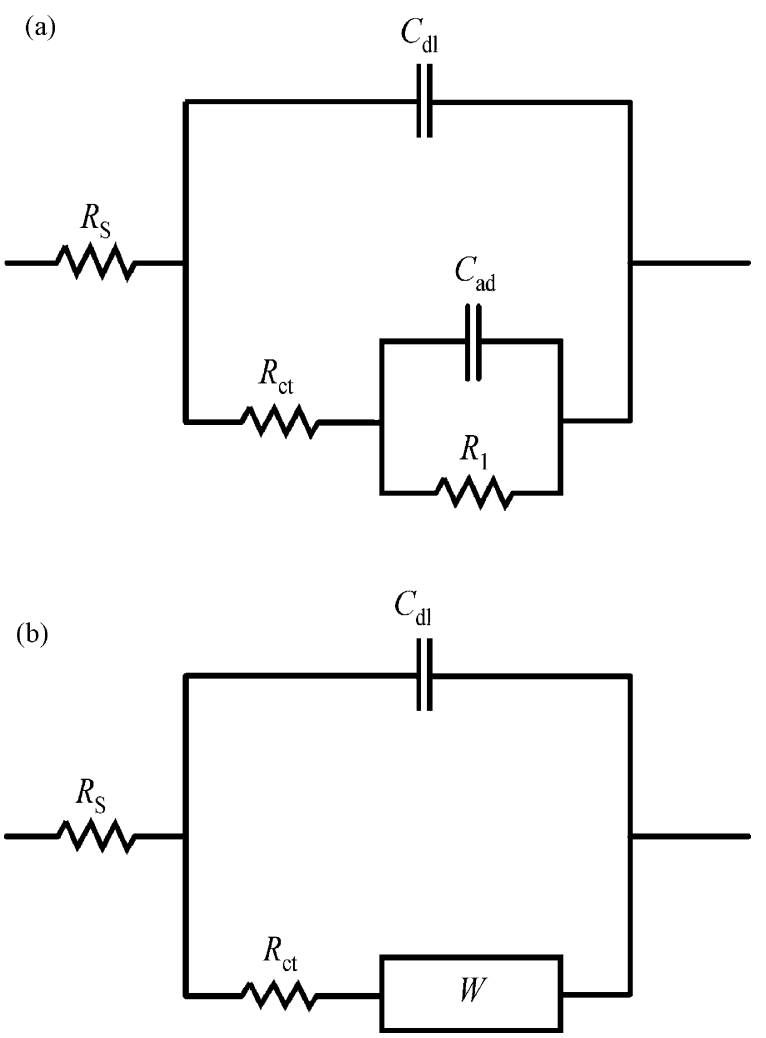

Fig. 4. Equivalent circuits (a) and (b) utilised to fit experimental EIS data. (a) Data obtained at $E=-0.45 \mathrm{~V}$. (b) Data obtained at $E=-0.50,-0.55,-0.60$ and $-0.65 \mathrm{~V}$. Fitting parameters are assembled in Tables 2-4.

protrusions presumably turn into active tips producing an enhancement of copper electrodeposition. Furthermore, in Nyquist plots from solution $C$ at $E=-0.45 \mathrm{~V}$ utilising an electrodeposited copper cathode prepared at $E=-0.65 \mathrm{~V}$ (not shown), the quasi-pure resistance observed in the medium range of $f$ smears out, and a Warburg-type behaviour follows the first complex loop at higher values of $f$. This fact indicates the key role played by the initial surface in the electrodeposition process.

\subsubsection{Influence of sodium chloride concentration}

Nyquist plots obtained at $E=-0.45$ and $-0.50 \mathrm{~V}$ from MPSAcontaining solutions with $10 \leq c_{\mathrm{NaCl}} \leq 2200 \mu \mathrm{M}$, in the absence of PEG, show a rather well-defined semicircle at the high values of $f$, and a Warburg-type behaviour at lower $f$.

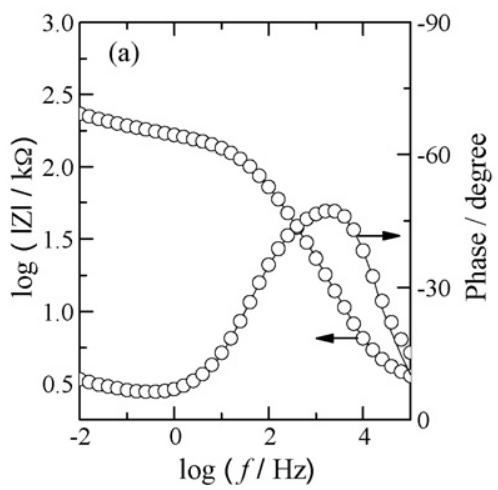

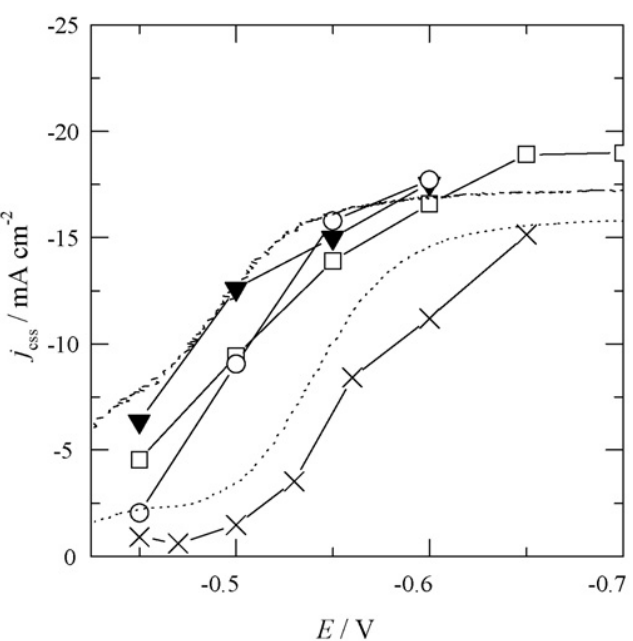

Fig. 6. Reconstructed polarisation curves from stationary currents resulting from potentiostatic current transients run simultaneously with EIS measurements. ( $\square$ ) Solution B; $(x)$ solution C; $(\boldsymbol{v})$ solution $\mathrm{D} ;(\bigcirc)$ solution $\mathrm{D}$. Polarisation curves run at $v=1 \mathrm{mV} \mathrm{s}^{-1}$ are included. The solid trace corresponds to data from solution $\mathrm{B}$, and the dotted trace to data from solution $\mathrm{C}$.

For $c_{\mathrm{NaCl}}<250 \mu \mathrm{M}$, values of $R_{\mathrm{ct}}$ from the EIS data fitting at $E=-0.45$ and $-0.50 \mathrm{~V}$ approach a linear $R_{\mathrm{ct}}$ versus square root of $c_{\mathrm{NaCl}}$ dependence, whereas for $c_{\mathrm{NaCl}}>250 \mu \mathrm{M}$, values of $R_{\mathrm{ct}}$ fluctuate around a constant figure (Fig. 7). As $E$ is shifted negatively, copper electrodeposition becomes convective-diffusion-controlled. Correspondingly, the value of $c_{\mathrm{NaCl}}$ at the cathode surface tends to zero as copper cathode-chloride species repulsive interactions increase. Then, the MPSA-chloride ion synergetic accelerating effect becomes much less significant, and $R_{\mathrm{ct}}$ becomes independent of $c_{\mathrm{NaCl}}$. These results are consistent with the cathodic limiting current resulting from polarisation curves, irrespective of the plating solution composition.

\subsubsection{Chloride-ion-free plating solutions containing either MPSA or PEG}

The preceding results indicate the convenience to explore the behaviour of chloride-free, additive-containing copper plating solutions. Nyquist plots from solutions $F$ and $G$ at different potentials are depicted in Fig. 8. For PEG-containing solution (solution $\mathrm{F}$ ) at $E=-0.50 \mathrm{~V}$ the Nyquist plot shows a single semicircle in the range $100 \mathrm{kHz}>f>10 \mathrm{~Hz}$ with $R_{\mathrm{ct}} \cong 12 \Omega \mathrm{cm}^{-2}$ at $10 \mathrm{~Hz}$, in contrast to the plot resulting from chloride-PEG-containing solutions that display a semicircle in the range $100 \mathrm{kHz}>f \geq 0.1 \mathrm{~Hz}$

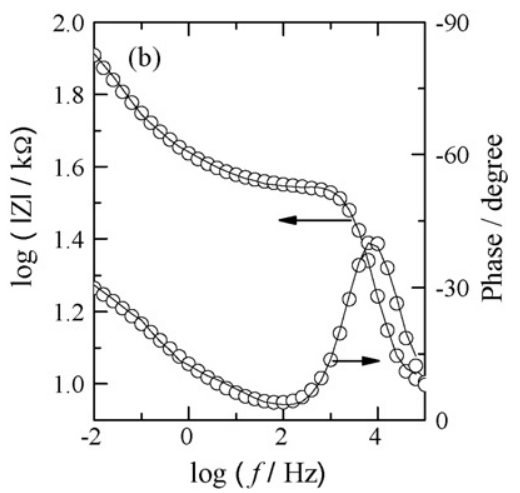

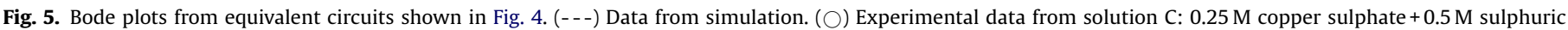
acid $+2.2 \mathrm{mM} \mathrm{NaCl}+880 \mu \mathrm{M}$ PEG. (a) $E=-0.45 \mathrm{~V}$. (b) $E=-0.60 \mathrm{~V}$. 


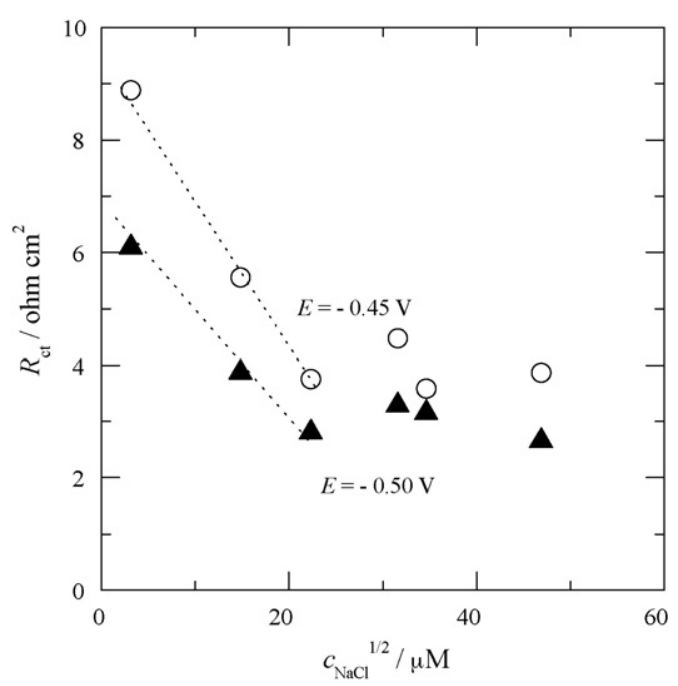

Fig. 7. Charge transfer resistance $\left(R_{\mathrm{ct}}\right)$ versus $c_{\mathrm{NaCl}}^{1 / 2}$ plot. Linear relationships are fulfilled for $E=-0.45$ and $-0.50 \mathrm{~V}$ and $c_{\mathrm{NaCl}}<220 \mu \mathrm{M}$. For $E=-0.50 \mathrm{~V}$ the largest data dispersion is observed.

with $R_{\mathrm{ct}} \cong 20 \Omega \mathrm{cm}^{-2}$ at $0.1 \mathrm{~Hz}$. Conversely, this difference in the behaviour of these solutions becomes less significant at $E=-0.55 \mathrm{~V}$.

The Nyquist plot from MPSA-containing solution (solution $G$ ) at $E=-0.50 \mathrm{~V}$ exhibits a first flat semicircle that extends in the range $100 \mathrm{kHz}>f \geq 0.1 \mathrm{~Hz}$, followed by a tendency to display a second one at lower frequency. On the other hand, the Nyquist plot from chloride-containing MPSA solution at $E=-0.50 \mathrm{~V}$ also dis-
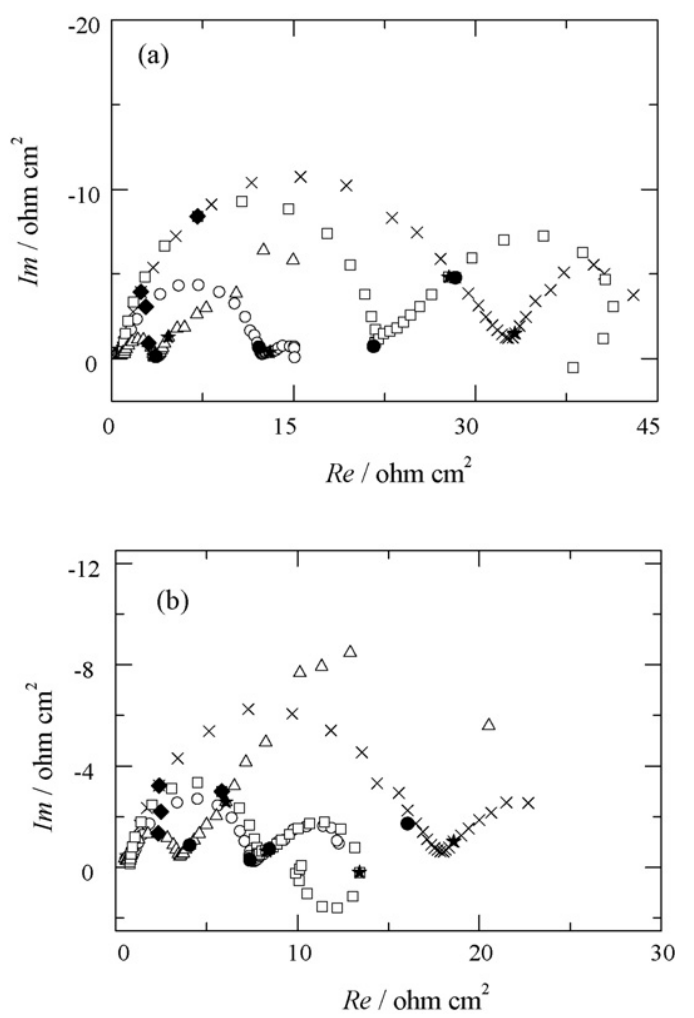

Fig. 8. Nyquist plots for copper electrodeposition from chloride-free and chloridecontaining plating solutions. (a) $E=-0.50$ V. (b) $E=-0.55$ V. ( $\bigcirc)$ Solution F. $(x)$ Solution G. $(\square)$ Solution C. $(\triangle)$ Solution D. Frequency values are indicated: $(\bullet)$ $1000 \mathrm{~Hz} ;(\bullet) 10 \mathrm{~Hz} ;\left(^{*}\right) 0.1 \mathrm{~Hz}$. plays the first well-defined semicircle, although for $f>1 \mathrm{kHz}$. The same description applies to the Nyquist plots from solution $G$ at $E=-0.55 \mathrm{~V}$. In this case, the first semicircle can be related to the charge transfer process, and the second one to MPSA adsorption, involving a moderate sulphur-copper surface interaction energy, as expected [44]. The equivalent circuit described in Section 3.2 (Fig. 4a) was used to fit EIS data at $E=-0.50 \mathrm{~V}$ (Table 4).

In agreement with the impedance associated with the first time constant, the values of $j_{\text {css }}$ at $E=-0.50 \mathrm{~V}$ indicate that copper electrodeposition rate for solution $\mathrm{F}$ is larger than for solution G. Therefore, at this potential, MPSA slightly inhibits copper electrodeposition.

It should be noted, however, that for the presence of either MPSA or PEG additive in the plating solution, the flattening of the first semicircle might also be related to the fractal characteristics of copper electrodeposits because no levelling action takes place in those cases [45].

\subsection{Thallium underpotential electrodeposition/anodic stripping on copper}

The adsorption of organic additives on copper was followed throughout changes caused by the possible MPSA and PEG adsorption on (upd)/anodic stripping on copper. These voltammograms were run in the potential range where $\mathrm{Tl} / \mathrm{Cu}$ alloying effects become negligible [46-49] (Fig. 9a and b).

In the absence of additives (blank) the voltammogram exhibits three rather poorly defined thallium upd current peaks (Ic, IIc, IIIc) at $-0.92,-0.96$ and $-1.02 \mathrm{~V}$, respectively. These cathodic current peaks partly overlap the hydrogen ion electroreduction current. Thallium stripping displays three current peaks (Ia, IIa, IIIa) at $E=-0.95,-0.91$ and $-0.87 \mathrm{~V}$. The anodic charge density, $0.37 \mathrm{mC} \mathrm{cm}^{-2}$, is close to that expected for three monolayers of thallium on copper $[34,46,47]$. It is known that both the anodic charge density and thallium upd peak multiplicity depend on the substrate treatment [47]. Thus, the thallium upd/anodic stripping voltammogram (Fig. 9b) on a copper electrode previously immersed for $10 \mathrm{~min}$ in $880 \mu \mathrm{M}$ PEG $+0.5 \mathrm{M} \mathrm{H}_{2} \mathrm{SO}_{4}$ solution still shows the current peak multiplicity of the blank, although the current peaks become rounded and the peak Ia/Ila current ratio is reversed. Similarly, for a copper electrode after emersion from aqueous $880 \mu \mathrm{M}$ $\mathrm{PEG}+0.5 \mathrm{M} \mathrm{H}_{2} \mathrm{SO}_{4}+2.2 \mathrm{mM} \mathrm{NaCl}$ (Fig. 9c), the decrease in the charge density determined from the anodic stripping peaks is about $5 \%$, i.e., there is a low copper coverage by PEG, at least in the potential range where the thallium upd/anodic stripping process takes place.

Comparable voltammetric features are observed in the respective polarisation curve (Fig. 1d). The increase in the cathodic potential results in a large increase in the cathodic current density as the PEG-copper chloride-mediated complex/copper surface interaction decreases.

Conversely, the voltammogram run in $0.1 \mathrm{mM}$ thallium sulphate $+0.5 \mathrm{M} \mathrm{H}_{2} \mathrm{SO}_{4}$ on a copper electrode that has been previously immersed in aqueous $125 \mu \mathrm{M} \mathrm{MPSA}+0.5 \mathrm{M} \mathrm{H}_{2} \mathrm{SO}_{4}$ at open circuit for $10 \mathrm{~min}$ (Fig. 9d) shows no thallium upd/anodic stripping current peaks. The voltammetric charge density, $0.29 \mathrm{mC} \mathrm{cm}^{-2}$, indicates about $20 \%$ copper surface coverage by MPSA, in agreement with a moderate MPSA adsorption. The voltammogram from a similar run made with a copper electrode after emersion from aqueous $125 \mu \mathrm{M}$ MPSA $+2.2 \mathrm{mM} \mathrm{NaCl}+0.5 \mathrm{M} \mathrm{H}_{2} \mathrm{SO}_{4}$ exhibits only peak IIIc (Fig. 9e). In this case, the voltammetric charge density, $0.31 \mathrm{mC} \mathrm{cm}^{-2}$, corresponds to $15 \%$ copper surface coverage by either MPSA or MPSA-chloride ion complex species. 
Table 4

Parameters used for fitting EIS data from chloride-free plating solution

\begin{tabular}{|c|c|c|c|c|c|c|c|}
\hline Solution & $j_{\mathrm{css}}\left(\mathrm{Acm}^{-2}\right)$ & $R_{\mathrm{s}}\left(\Omega \mathrm{cm}^{2}\right)$ & $C_{\mathrm{dl}}\left(\mu \mathrm{Fcm}^{-2}\right)$ & $\alpha$ & $R_{\mathrm{ct}}\left(\Omega \mathrm{cm}^{-2}\right)$ & $C_{\mathrm{ad}}\left(\mu \mathrm{Fcm}^{-2}\right)$ & $R_{1}\left(\Omega \mathrm{cm}^{2}\right)$ \\
\hline \multicolumn{8}{|c|}{$E=-0.50 \mathrm{~V}$ (versus SSE) } \\
\hline $\mathrm{F}$ & 4.5 & 0.12 & 45.7 & 0.99 & 7.81 & 847.5 & 18.02 \\
\hline G & 2.1 & 0.40 & 40.5 & 0.99 & 4.73 & 1129.0 & 37.96 \\
\hline
\end{tabular}

\subsection{SEM micrographs of copper electrodeposits}

SEM micrographs of $10 \mathrm{mC} \mathrm{cm}^{-2}$ copper layers electrodeposited on faced down copper sheet electrodes together with the working condition of each run are shown in Fig. 10.

The micrograph of electrodeposits resulting from solution $B$ at $E=-0.45 \mathrm{~V}$ shows highly anisotropic faceted crystals with $60^{\circ}$ and $120^{\circ}$ angles at face and step borders. The average crystal size is $1.4 \pm 0.6 \mu \mathrm{m}$. The same features are observed for the electrodeposit made at $E=-0.50$ and $-0.55 \mathrm{~V}$, except for the decrease in the average crystal size to $0.86 \pm 0.36 \mu \mathrm{m}$ at $E=-0.50 \mathrm{~V}$, and its slight increase to $1.2 \pm 0.4 \mu \mathrm{m}$ at $E=-0.55 \mathrm{~V}$.

Conversely, the SEM micrograph of electrodeposits obtained from solution $C$ at $E=-0.45 \mathrm{~V}$ exhibits polyfaceted crystallites $0.8 \pm 0.4 \mu \mathrm{m}$ in average size. Coalesced neighbour crystals tend to produce a percolated pattern with randomly distributed holes. This fact is consistent with an initial phase growth regime without nucleation [13] followed by random growth at unstable surface sites. For $E=-0.50 \mathrm{~V}$, the electrodeposit becomes more homogeneous, its average crystal size is $0.4 \pm 0.2 \mu \mathrm{m}$. For $E=-0$. $55 \mathrm{~V}$ aggregates of about $2 \mu \mathrm{m}$ in average diameter and a large number density of smaller ones are observed.

The micrographs of copper electrodeposits made from solution $\mathrm{D}$ at both $E=-0.45$ and $-0.50 \mathrm{~V}$ reveal large and small, irregular crystal domains, the average crystal size being $1.3 \pm 0.60 \mu \mathrm{m}$. In contrast, the copper cathode resulting at $E=-0.55 \mathrm{~V}$ exhibits large mounds of $2.0 \pm 0.2 \mu \mathrm{m}$ average crystal size.

The micrograph obtained from solution $\mathrm{E}$ at $E=-0.45 \mathrm{~V}$ is rather similar to that from solution D. Surprisingly, for $E=-0.50$ and $-0.55 \mathrm{~V}$, large crystalline domains cover a smooth electrodeposited copper surface up to about $40 \%$. The smooth electrodeposit domains at $E=-0.55 \mathrm{~V}$ resemble that obtained from solution $\mathrm{D}$ at the same potential.

At constant $E$ both the value of $j_{\text {css }}$ and the average crystal size of the electrodeposit decrease in going from the accelerantcontaining to the inhibitor-containing solutions.

\section{Discussion}

\subsection{Preliminary considerations}

The electrodeposition of copper from additive-containing aqueous solutions on a solid conducting substrate implies several copper surface/solution constituent interactions playing a relevant role in the kinetics of the process. The overall copper electrodeposition pathway comprises electron transfer reactions, either adsorption or electrosorption of reactants, intermediates and products at the growing copper surface, competitive adsorption equilibrium and transport phenomena from the solution, and presumably surface diffusion of adsorbates. The relative contribution of each process
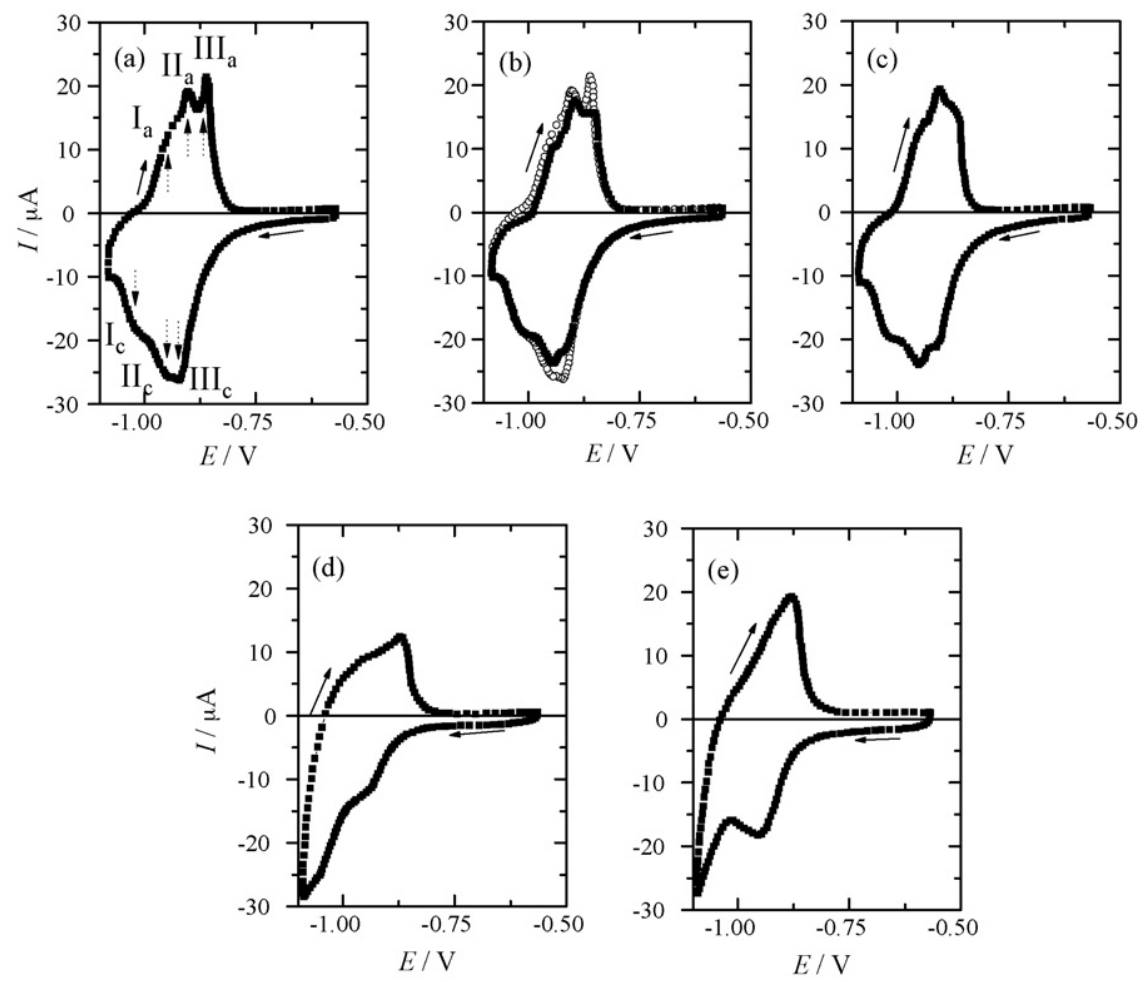

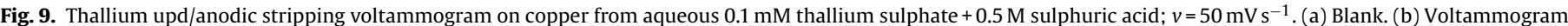

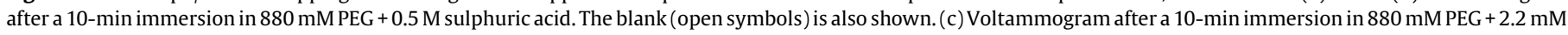

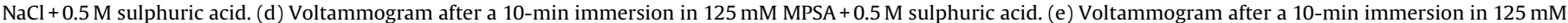
$\mathrm{MPSA}+2.2 \mathrm{mM} \mathrm{NaCl}+0.5 \mathrm{M}$ sulphuric acid. 

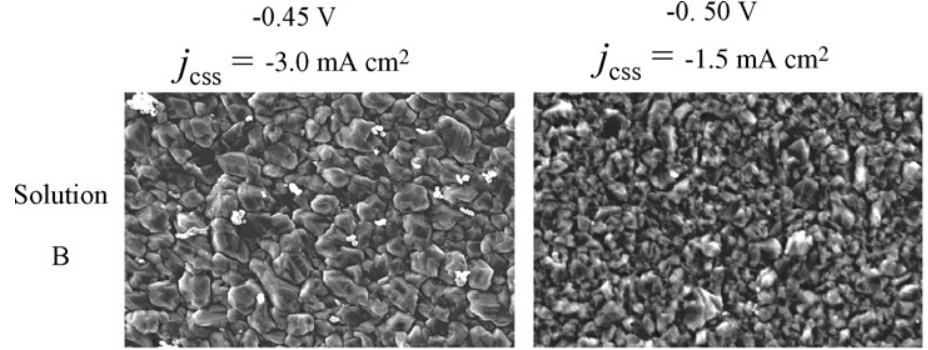

$-0.45 \mathrm{~V}$
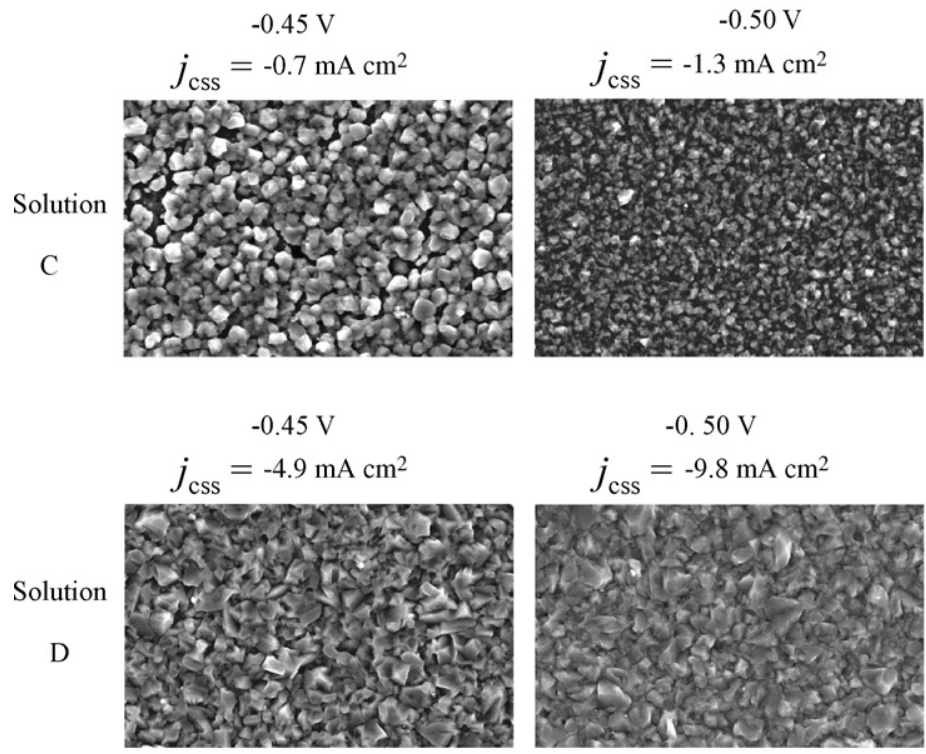

D
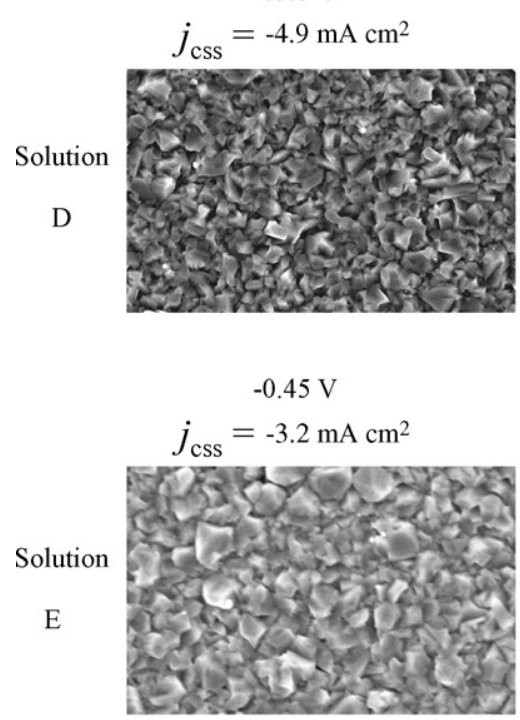

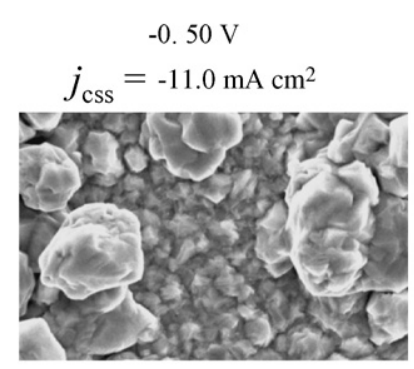

$10 \mu \mathrm{m}$
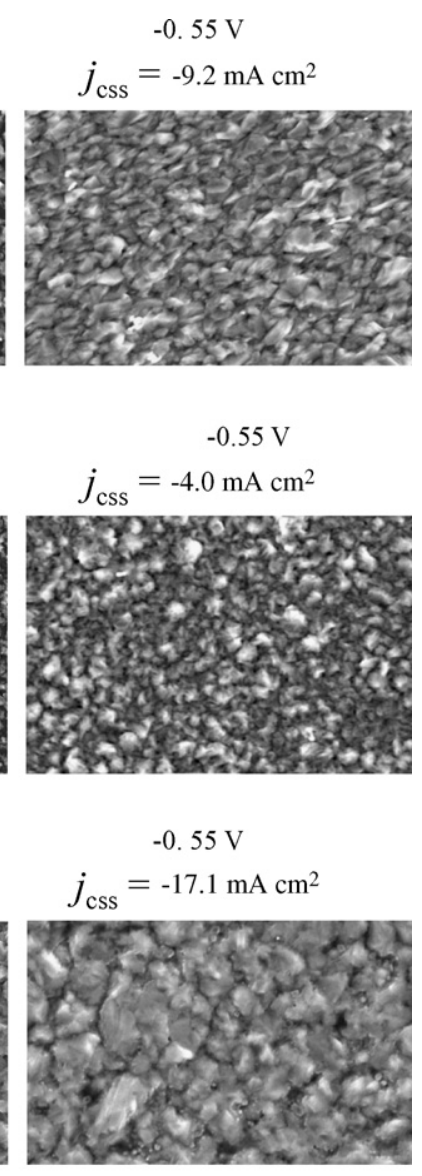

$-0.55 \mathrm{~V}$

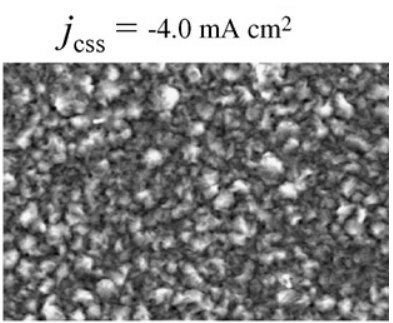

$-0.55 \mathrm{~V}$

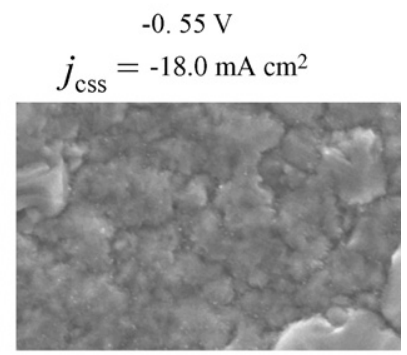

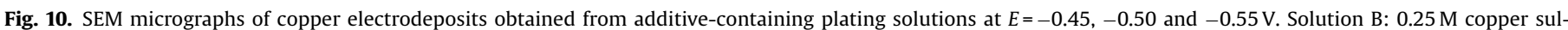

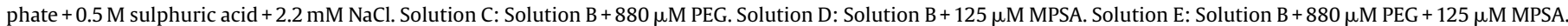
Stationary current densities are indicated.

depends also on the electrical perturbation routine selected to drive the electrochemical system. This brief description takes for granted that all these contributions are co-operatively interrelated.

For a rational approach to surface processes involving the adsorption of additives, the potential of zero charge $\left(E_{\mathrm{pzc}}\right)$ of the copper electrode in the aqueous environments is of great interest. Its value, either for single-crystal or polycrystalline copper, changes considerably due to specific adsorption of both ions and additives [50]. The values of $E_{\mathrm{pzc}}$ for copper in different environments show a rather large discrepancy as they go from -1.06 to $-0.56 \mathrm{~V}$ (versus SSE), depending on the electrolyte and measuring method [50,51]. A value around $-1.36 \mathrm{~V}$ (versus SSE) for the $E_{\mathrm{pzc}}$ of either singlecrystal or polycrystalline copper in neutral and acidic perchlorate solutions has been recently reported [52]. Besides the composition of the solution, this discrepancy may be due to the ease of copper electrode surface oxidation [52] and to the procedure utilised for the preparation of the copper surface [50].

For our polycrystalline copper samples, the likely value $E_{\mathrm{pzc}} \cong-0.56 \mathrm{~V}$, a figure close to the potential at which noticeable changes in the EIS data are observed, particularly for PEGcontaining solutions (Fig. 3), was considered.

\subsubsection{Copper electrodeposition in the absence of additives}

The kinetics and mechanism of polycrystalline and singlecrystal copper electrodes, as well as their surface morphology changes produced by both the anodic and cathodic processes in aqueous electrolyte solutions containing common constituents, have been extensively studied under different experimental conditions [53-55]. Briefly, under stationary conditions, copper electrodeposition has been interpreted by two consecutive charge 
transfer steps

$\mathrm{Cu}^{2+}(\mathrm{aq})+\mathrm{e}^{-}=\mathrm{Cu}^{1+}(\mathrm{aq})$

$\mathrm{Cu}^{1+}(\mathrm{aq})+\mathrm{e}^{-}=\mathrm{Cu}^{0}(\mathrm{~s})$

and the heterogeneous equilibrium

$2 \mathrm{Cu}^{1+}(\mathrm{aq})=\mathrm{Cu}^{2+}(\mathrm{aq})+\mathrm{Cu}^{0}(\mathrm{~s})$

Further details of the process, particularly related to the initial stages of the copper phase growth, have been investigated by means of non-stationary techniques and surface microscopy, as is summarised in references [56,57].

\subsubsection{Chloride ion-containing solutions}

The addition of chloride ions to copper plating solutions is a well-known practice to form aqueous $\mathrm{Cu}(\mathrm{I})$-chloride ion complexes and to originate rather strong chloride ion-copper surface adsorption interactions to modify the kinetics of copper electrodeposition [58]. Despite the uncertainty in the $E_{\mathrm{pzc}}$ value, as indicated above, at a low cathodic overpotential and a chloride ion concentration larger than $10^{-3} \mathrm{M}$, most of the copper surface becomes covered by chloride-containing species [59]. Depending on the chloride ion concentration in solution, a copper-chloride complex precipitates onto the surface and hinders the electrodeposition [60,61]. In these plating solutions the anisotropy of copper electrodeposits has been attributed to distinct copper-chloride ion complexes in solution interacting with different copper surface lattice sites. For certain working potential ranges, all these facts become rate- and electrodeposit morphology-determining [62].

The electrodeposition of copper from chloride-containing copper plating solutions in the absence of organic additives has been regarded as a complex reaction involving two elementary steps [61]

$\mathrm{Cu}^{2+}+2 \mathrm{Cl}^{-}+\mathrm{e}^{-} \Leftrightarrow \mathrm{CuCl}_{2}^{-}$

$\mathrm{CuCl}_{2}{ }^{-}+\mathrm{e}^{-} \Leftrightarrow \mathrm{Cu}+2 \mathrm{Cl}^{-}$

Step (4), the first electron transfer yields a copper dichloride complex ion, the reduction of $\mathrm{Cu}(\mathrm{II})$ to $\mathrm{Cu}(\mathrm{I})$ being the rate-determining step. Step (5) is a fast electron transfer that completes the reduction of $\mathrm{Cu}(\mathrm{I})$ to $\mathrm{Cu}(0)$. This consecutive reaction pathway is formally analogous to that reported for copper ion discharge from aqueous sulphate-containing acid solutions [53-55]. Steps (4) and (5) are coupled to the following equilibria

$$
\begin{aligned}
& \mathrm{Cu}^{+}+\mathrm{Cl}^{-} \Leftrightarrow \mathrm{CuCl} \\
& \mathrm{CuCl}+\mathrm{Cl}^{-} \Leftrightarrow \mathrm{CuCl}_{2}^{-}
\end{aligned}
$$

For this type of copper plating solution, chloride ions stabilise $\mathrm{Cu}(\mathrm{I})$ species via reactions (4)-(7), and eventually a $\mathrm{CuCl}$ film formed on the copper surface hinders the process.

The preceding mechanistic approach is useful for discussing data of copper electrodeposition from chloride-containing plating solutions in the presence of organic additives, considering first possible interactions of additives in the electrochemical system.

\subsection{The interactions of MPSA and PEG with chloride-free and chloride containing copper plating solutions}

\subsubsection{MPSA}

The addition of MPSA to chloride-free cupric ion-containing solutions produces both a $\mathrm{Cu}(\mathrm{I})$ and a $\mathrm{Cu}$ (II) complex in the aqueous solution via the participation of $-\mathrm{SH}$ and $\mathrm{SO}_{3}{ }^{-2}$ moieties $[35,63]$. Thermodynamic data of a number of possible MPSA-copper complexes have already been reported [9]. Their interactions with the copper surface depend on the concentration of constituents in the bulk of the solution and at the reaction interface. The adsorption energy of MPSA on copper of about $40 \mathrm{~kJ} / \mathrm{mol}$ suggests moderate MPSA/copper surface interaction [34].

For chloride-free plating solutions a partial cathode blocking by MPSA occurs from -0.55 to $-0.70 \mathrm{~V}$, as concluded from the polarisation curve (Fig. 1e), in agreement with the charge transfer resistance derived from EIS data (Fig. 8) and the moderate decrease in the electrode surface area derived from the comparison of thallium upd/anodic stripping voltammograms depicted in Fig. 9a and d. The shoulder from -0.45 to $-0.50 \mathrm{~V}$ in the polarisation curve has been related to the cathodic discharge of cuprous ions stabilised by thiolate species produced from MPSA [9]. Accordingly, the reactions involving MPSA either in the bulk of the solution or at the copper surface can be written as

$\mathrm{Cu}+\mathrm{Cu}^{2+}+2 \mathrm{MPSA} \Leftrightarrow 2 \mathrm{Cu}(\mathrm{I})($ thiolate $) \mathrm{ad}+2 \mathrm{H}^{+}$

$4 \mathrm{MPSA}+2 \mathrm{Cu}^{2+} \Leftrightarrow 2 \mathrm{Cu}(\mathrm{I})(\text { thiolate })_{\mathrm{ad}}+\mathrm{SPS}+4 \mathrm{H}^{+}$

SPS being the disulphur derivative of MPSA.

Reaction (9) is thermodynamically favoured when the concentration of cupric ions is smaller than that of MPSA [9]. Reactions (8) and (9) are coupled to the competitive adsorption equilibrium of MPSA and PEG species discussed further on.

For chloride-containing solutions, the presence of MPSA accelerates copper electrodeposition, as can be inferred from both the polarisation curve at low cathodic overpotential (Fig. 1f) and EIS data (Figs. 2, 3 and 8). In this case, the thallium upd/anodic stripping voltammogram with a copper electrode previously immersed in solution $\mathrm{D}$ shows a smaller decrease in surface area and different voltammetric features as compared to chloride-free MPSA-containing solution (Fig. 9d and e). These results are consistent with a potential-depending co-operative MPSA-chloride interaction at the copper/solution interface that can be expressed by

$\mathrm{CuCl}_{\mathrm{ad}}+\mathrm{MPSA} \Leftrightarrow \mathrm{Cu}(\mathrm{I})(\text { thiolate })_{\mathrm{ad}}+\mathrm{Cl}^{-}+\mathrm{H}^{+}$

The $\mathrm{Cu}(\mathrm{I})(\text { thiolate })_{\text {ad }}$ species involved in this competitive adsorption equilibrium has been considered as the true accelerant for copper electrodeposition [9].

\subsection{2. $P E G$}

For chloride-free aqueous solution, the interaction of PEG with the copper surface is poor, as is inferred from the upd/anodic stripping voltammogram obtained after immersion in solution $\mathrm{F}$ (Fig. 9b). Likewise, the polarisation curve from solution F (Fig. 1c) approaches that from solution A (Fig. 1a).

In the presence of chloride ions, the adsorption of PEG or PEG-copper chloride-mediated complexes on copper is rather significant at the beginning of the polarisation curve, i.e., the current density increases slowly for $E>-0.50 \mathrm{~V}$ (Fig. 1d) and EIS data (Fig. 2) that exhibit a first loop with a large impedance. These results can be explained by the competitive equilibrium between adsorbed Cu-chloride adsorbates and PEG proposed in reference [9],

$n \mathrm{CuCl}_{\mathrm{ad}}+\mathrm{HO}\left[\left(\mathrm{CH}_{2}\right)_{x} \mathrm{O}\right]_{y} \mathrm{H} \Leftrightarrow\left\{\mathrm{HO}\left[\left(\mathrm{CH}_{2}\right)_{x} \mathrm{CuCl}\right]_{n}\left[\left(\mathrm{CH}_{2}\right)_{x} \mathrm{O}\right]_{y-n} \mathrm{H}\right\}_{\text {ad }}$

For $E<-0.55 \mathrm{~V}$ the copper coverage by PEG-chloride complexes diminishes as the cathode negative charge is increased [64].

During copper electrodeposition the PEG-Cu-chloride complex is partially desorbed from the surface as concluded from our EIS data at low frequencies (inductive loop) (Fig. 2). The adsorption/desorption of the PEG-Cu-chloride complex that takes place at a critical potential depends on the solution composition and $\mathrm{pH}$. Furthermore, as the PEG/Cu-chloride concentration ratio in the plating solution exceeds a certain critical value, copper electrodeposition is hindered [37]. Then, from all these results it is reasonable 
to conclude that the PEG-Cu-chloride complex species are loosely adsorbed and produce a combined blocking and pinning effect [65]. The latter results from the low mobility of these adsorbates over the copper surface that interferes with the surface diffusion of depositing copper ions or atoms to locate at stable surface lattice sites. Correspondingly, the yield of copper electrodeposition from these plating solutions will increase as the PEG-copper chloridemediated adsorbed layer is either partially or completely removed from the copper surface. The formation of PEG-copper chloridemediated adsorbates has been concluded by surface-enhanced Raman spectroscopy and other techniques [14,15,17,19,24,26-30].

Let us now consider chloride-based plating solutions containing both MPSA and PEG. In this case, PEG-copper chloride-mediated adsorbates from reaction (11) should be coupled to $\mathrm{Cu}$-thiolate adsorbates by the following competitive adsorption equilibrium [9]

$$
\begin{aligned}
& \left\{\mathrm{HO}\left[\left(\mathrm{CH}_{2}\right)_{x} \mathrm{OCuCl}\right]_{n}\left[\left(\mathrm{CH}_{2}\right)_{x} \mathrm{O}\right]_{y-n} \mathrm{H}\right\}_{\text {ad }} \\
& +n \mathrm{MPSA} \Leftrightarrow\left\{\mathrm{HO}\left[\left(\mathrm{CH}_{2}\right)_{x} \mathrm{O}\right]_{y} \mathrm{H}\right\}+n \mathrm{Cl}^{-}+\mathrm{nH}^{+} n \mathrm{Cu}(\mathrm{I}) \text { thiolate }
\end{aligned}
$$

where $\left\{\mathrm{HO}\left[\left(\mathrm{CH}_{2}\right)_{x} \mathrm{OCuCl}\right]_{n}\left[\left(\mathrm{CH}_{2}\right)_{x} \mathrm{O}\right]_{y-n} \mathrm{H}\right\}_{\text {ad }}$ is an adsorbed PEG$\mathrm{Cu}(\mathrm{I})$-chloride ion, and $\left\{\mathrm{HO}\left[\left(\mathrm{CH}_{2}\right)_{x} \mathrm{O}\right]_{y} \mathrm{H}\right\}$ stands for PEG. Reaction (12) imposes an adsorbate size restriction on the average number of copper adsorption sites covered by a single either PEG $\left(n^{\prime}\right)$ or MPSA $(n)$ molecule $\left.\left.\left(n^{\prime}\right\rangle\right) n\right)$. The actual number of surface sites available for copper electrodeposition should be determined by both the PEG and MPSA concentration in the plating solution and the value of the $n^{\prime} / n$ ratio for both PEG and MPSA at each value of $E$.

\subsection{Likely pathways for copper electrodeposition in the presence of additives}

In additive-containing plating solutions, the polarisation curves run (negative potential excursion) at $E>-0.55 \mathrm{~V}$ show significant changes with the solution composition (Fig. 1). At low cathodic overpotentials, these changes are assigned to a synergism of chloride ions and organic additives. In the presence of MPSA this synergism accelerates copper electrodeposition via $\mathrm{Cu}(\mathrm{I})$ soluble species, whereas in the presence of PEG it inhibits the reaction by blocking and pinning effects (Figs. 2, 3 and 8).

For $E>-0.55 \mathrm{~V}$, the Nyquist plots (Fig. 2) and data from the equivalent circuits (Fig. 4, Tables 2 and 3 ) can be interpreted considering the MPSA-Cu(I)-chloride ion combined effect on copper electrodeposition as a consecutive reaction pathway, in which the cuprous species results from a chemical step preceding the accelerant adsorption, and the subsequent charge transfer step to reduce $\mathrm{Cu}(\mathrm{I})$ to $\mathrm{Cu}(0)$. The reaction pathway offers two possible options in consonance with the variation of $R_{\mathrm{ct}}$ with chloride concentration (Fig. 6). The first one considers the formation of cuprous species in the bulk of the solution

$$
\begin{aligned}
& \operatorname{MPSA}(\mathrm{aq})+\mathrm{Cu}^{2+}(\mathrm{aq})+\mathrm{e}^{-} \Leftrightarrow[\mathrm{MPSCu}](\mathrm{aq})+\mathrm{H}^{+}(\mathrm{aq}) \\
& {[\mathrm{MPSCu}](\mathrm{aq})+\mathrm{Cl}^{-}(\mathrm{sol}) \Leftrightarrow[\mathrm{MPSCu}] \mathrm{Cl}^{-}(\mathrm{aq})} \\
& {[\mathrm{MPSCu}] \mathrm{Cl}^{-}(\mathrm{aq}) \Leftrightarrow[\mathrm{MPSCu}] \mathrm{Cl}^{-}(\mathrm{ad})}
\end{aligned}
$$

$[\mathrm{MPSCu}] \mathrm{Cl}^{-}(\mathrm{ad})+\mathrm{H}^{+}(\mathrm{aq})+\mathrm{e}^{-} \Leftrightarrow \mathrm{Cu}(\mathrm{s})+\mathrm{Cl}^{-}(\mathrm{aq})+\mathrm{MPSA}(\mathrm{aq})$

The second option first produces a cuprous chloride intermediate that is adsorbed; this adsorbate reacts with MPSA to form the accelerant, and eventually the electroreduction from the MPSA-cuprous complex to $\mathrm{Cu}(\mathrm{s})$ takes place,

$$
\begin{aligned}
& \mathrm{Cu}^{+}(\mathrm{aq})+\mathrm{Cl}^{-}(\mathrm{aq}) \Leftrightarrow \mathrm{CuCl}(\mathrm{ad}) \\
& \mathrm{CuCl}(\mathrm{ad})+\mathrm{Cl}^{-}(\mathrm{aq}) \Leftrightarrow\left[\mathrm{CuCl}_{2}{ }^{-}\right](\mathrm{ad})
\end{aligned}
$$

$\left[\mathrm{CuCl}_{2}{ }^{-}\right](\mathrm{ad})+\operatorname{MPSA}(\mathrm{aq}) \Leftrightarrow[\mathrm{MPSCu}](\mathrm{ad})+2 \mathrm{Cl}^{-}(\mathrm{aq})+\mathrm{H}^{+}(\mathrm{aq})$

$[\mathrm{MPSCu}](\mathrm{ad})+\mathrm{H}^{+}(\mathrm{aq})+\mathrm{e}^{-} \Leftrightarrow \mathrm{Cu}(\mathrm{s})+\operatorname{MPSA}(\mathrm{aq})$

According to recently reported ring/disc data [9], the second mechanism appears to be more plausible.

The fact that PEG complexes affect the copper electrodeposit morphology at all cathodic overpotentials, suggest an unbalance produced between the chemical surface interaction, which depends on the adsorption energy and the surface concentration of chloride ions, and the blockage and pinning effects resulting from the large average size of PEG molecules and their low mobility on the copper surface. The inductive loop in the Nyquist plot from solution $C$ at $E=-0.50 \mathrm{~V}$ appears in the range of time $10^{-1} \leq t \leq 10 \mathrm{~s}$ that is comparable to the average time required by $\mathrm{PEG}(\mathrm{PM}=400)$ colloidal particles to travel an average distance $d$ without colliding with a neighbour particle in the solution. Taking the activation energy for surface diffusion of PEG $\Delta E_{\mathrm{D}}^{*} \cong 10 \mathrm{~kJ} / \mathrm{mol}$ [7], for $f=1 \mathrm{~Hz}$, the average surface diffusion coefficient of PEG adsorbates on copper results of the order of $D \approx 10^{-8} \mathrm{~cm}^{2} \mathrm{~s}^{-1}$. Then, the average surface relaxation distance of PEG adsorbates would be in the range $0.01 \leq d \leq 1 \mu \mathrm{m}$. Therefore, the surface relaxation frequency of PEG adsorbates would tend to couple to the low-frequency range modulating potential, so that at the lowest values of $f$ their inhibiting effect would tend to disappear, as concluded from the Nyquist plot (Fig. 2).

At high cathodic overpotentials copper electrodeposition is under convective-diffusion control, all plating solutions approaching the same voltammetric cathodic limiting current density, irrespective of the topography of the copper-plated cathode. For low potential scanning, such as $1 \mathrm{mV} \mathrm{s}^{-1}$, the initiation of the positive potential excursion from $-0.97 \mathrm{~V}$ indicates a significant apparent increase in the cathodic current that can be related to an increase in the active surface area due to the large charge passed. However, from the electrochemical hydrodynamic standpoint, this increase in surface area should have no significant effect because the average thickness of the Nernst diffusion layer in our experiments becomes about twice the value of $350 \mu \mathrm{m}$ calculated for a vertical plane plate cathode [66], a figure largely in excess with respect to the largest copper protrusion size. Another possible explanation of the apparent increase in the cathodic current admits the local appearance of instabilities changing the growth mode regime to branching. Concomitantly, the distribution of the electrical field becomes non-uniform. Then, the electrochemical reaction at the tip of separate branches approaches the conditions prevailing at microelectrodes [67]. In fact, the electrodeposit topography (Fig. 10) resulting from different plating solutions at constant $E$ should depend on the cathodic current flow. Accordingly, the copper cathode initial roughness might introduce some uncertainty in the polarisation curves (Fig. 1) and EIS data (Tables 2-4).

Our data indicate a decrease in the adsorption of the PEGcopper chloride-mediated complex as $E$ is shifted negatively to $E=-0.65 \mathrm{~V}<E_{\mathrm{pzc}} \cong-0.56 \mathrm{~V}$. At this potential both the negatively charged cathode surface and the increase in the surface area of the growing electrodeposit might contribute to weaken the PEGchloride-mediated complex/copper surface interactions. The larger the stationary current density, the greater the above effect. This possibility is supported by the $E$-dependent change trend of EIS data and SEM micrographs of copper electrodeposits produced from different plating solutions (Fig. 10). Thus, for both solution B and C, the grain size of the electrodeposit first diminishes in going from $E=-0.45$ to $-0.50 \mathrm{~V}$, and then increases in going up to $E=-0.55 \mathrm{~V}$ as 
the growing copper phase becomes unstable. Therefore, it appears that the effect of chloride ions acting co-operatively with the changing electrodeposit topography is similar for both plating solutions.

Conversely, for solution D, no appreciable dependence of the grain size of the electrodeposit on $E$ is observed (Fig. 10), in contrast to solution E containing both PEG and MPSA. In this case, the instability of the growing electrodeposit leads to the appearance of large mounds. The appearance of these morphological features is reflected, at least in part, in the EIS data from the different plating solutions. Accordingly, data obtained from distinct initial copper topographies become particularly interesting, such as the dependence of the diameter of the EIS high-frequency loop (Table 3) and the disappearance of the EIS lower-frequency loop. Thus, EIS data recorded at $E=-0.45 \mathrm{~V}$ with an electrode previously electroplated at $E=-0.65 \mathrm{~V}$ exhibit the charge transfer loop at high $f$ and a Warburg-type diffusion line at low $f$, whereas at the middle range of $f$ the loop is absent. Then, the influence of the initial copper surface topography should be considered as a relevant variable of the process.

It is worth noting some similarities between recent published EIS data obtained at constant current in the range of activated copper electrodeposition [38,39] and data reported in this work. In the former case, EIS data features at high frequencies have been interpreted in terms of a charge transfer process, and at small frequencies, in terms of relaxation processes of the additives. In the Nyquist plots the inductive loop at the lowest frequencies was associated with desorption or adsorption/desorption processes involving accelerant species. The frequency range of the poorly defined loop after the charge transfer process has been interpreted as the PEG-copper chloride-mediated complex-copper surface interaction, in agreement with EIS data from solution $C$ at $E=-0.55 \mathrm{~V}$. In our work, the analysis of EIS under potential control from solutions C-E is limited to $f>0.1 \mathrm{~Hz}$ because of the large data scattering at lower frequencies. The latter effect can be ascribed to the change in the active surface area at the electrode surface (Fig. 10), being more significant for larger values of $j_{\text {css. }}$.

\section{Conclusions}

Voltammetric polarisation curves show that the rate-controlling process changes gradually from activation- to mixed- to mass transport-controlled as the applied potential increases negatively, irrespective of the solution composition. There is a complex synergism of chloride ions with both PEG and MPSA. In the absence of chloride ions, PEG adsorbs slightly on copper, whereas MPSA shows a moderate adsorption. At low electrodeposition potentials the presence of PEG and chloride ions slows down the copper electrodeposition rate, while the reverse effect occurs when the MPSA-chloride ion complex is produced.

EIS data fit the prediction of equivalent circuits utilising reasonable parameters for their electrical elements. The formation of a cathodic film from those solutions containing chloride ions, particularly in PEG-containing solution, can be concluded from Nyquist plots. At high electrodeposition potentials, this film is either partially or completely detached from the cathode. Due to its relatively high mobility (low interaction energy with the copper surface, $\mathrm{MW}=400, D_{\mathrm{s}}=10^{-8} \mathrm{~cm}^{2} \mathrm{~s}^{-1}$ ) its detachment can be noted in the Nyquist plots at low modulation frequency. It would be favoured when chloride ions are gradually drawn off from the copper surface as the applied potential increases negatively and the renewal of the depositing copper area is fast, as indicated by the large value of $j_{\text {css }}$ and the change in the electrodeposit average grain size with $E$.
Likely charge transfer reaction pathways involving at least three consecutive steps are discussed on the basis of the set of reactions proposed in earlier work [9]. For the sodium chlorideMPSA-containing plating solution, the reaction pathway comprises the formation of a $\mathrm{Cu}(\mathrm{I})$-thiolate complex (accelerant) that occurs either by homogeneous redox reaction and subsequent adsorption on copper, or by reaction of MPSA with previously adsorbed copper chloride species, followed, in both cases, by a fast electron transfer step yielding copper and MPSA.

For the sodium chloride-PEG-containing plating solution there is an influence of PEG complexes on the copper electrodeposit morphology that is explained by the physical interaction caused by pinning, i.e., the interference of low mobility adsorbates on the copper surface with the surface diffusion of depositing ions or atoms to reach stable surface lattice sites.

\section{Acknowledgements}

M.A.P., L.M.G. and A.J.A. are members of the Research Career (CONICET). This work was supported by Consejo Nacional de Investigaciones Científicas y Técnicas (CONICET), Comisión de Investigaciones Científicas de la Provincia de Buenos Aires (CIC), PICT 98 No. 06-03251 and PICT 34530, Agencia Nacional de Promoción Científica y Tecnológica (Argentina).

\section{References}

[1] W. Plieth, Electrochim. Acta 37 (1992) 2115.

[2] E.K. Yung, L.T. Romankiw, R.C. Alkire, J. Electrochem. Soc. 147 (1989) 206.

[3] T.R. Anthony, J. Appl. Phys. 52 (1981) 5340.

[4] P.C. Andricacos, C. Uzoh, J.O. Dukovik, J. Jorkans, H. Deligianni, IBM J. Res. Dev. 42 (1998) 567.

[5] P.C. Andricacos, Interface 1 (1998) 23.

[6] T.P. Moffat, J.E. Bonevich, W. Huber, A. Stanishevsky, D.R. Kelly, G.R. Stafford, D. Josell, J. Electrochem. Soc. 147 (2000) 4524.

[7] A.C. West, S. Mayer, J. Reid, Electrochem. Solid-State Lett. 4 (2001) C50.

[8] M.A. Pasquale, D.P. Barkey, A.J. Arvia, J. Electrochem. Soc. 152 (2005) C149.

[9] P.M. Vereecken, R.A. Binstead, H. Deligianni, P.C. Andricacos, IBM J. Res. Dev. 49 (2005) 3.

[10] D. Josell, D. Wheeler, W.H. Huber, T.P. Moffat, Phys. Rev. Lett. 81 (2001) 016102.

[11] D. Josell, D. Wheeler, W.H. Huber, T.P. Moffat, Electrochem. Solid-State Lett. 5 (2002) C49.

[12] Y. Cao, P. Taephaisitphongse, R. Chalupa, C. West, J. Electrochem. Soc. 148 (2001) C466.

[13] F.J. Rodríguez Nieto, M.A. Pasquale, M.E. Martins, F. Barieles, A.J. Arvia, Monte Carlo Methods Appl. 12 (2006) 271.

[14] K. Kondo, N. Yamakawa, Z. Tanaka, K. Hayashi, J. Electroanal. Chem. 559 (2003) 137.

[15] K. Kondo, T. Matsumoto, K. Watanabe, J. Electrochem. Soc. 151 (2004) C250.

[16] S.-E. Bae, A. Gewirth, Langmuir 22 (2006) 10315.

[17] Y. Jin, K. Kondo, Y. Suzuki, T. Matsumoto, D.P. Barkey, Electrochem. Solid-State Lett. 8 (2005) C6.

[18] D.M. Soares, S. Wasle, K.G. Weil, K. Doblhofer, J. Electroanal. Chem. 532 (2002) 353.

[19] J.J. Kim, S.-K. Kim, Y.S. Kim, J. Electroanal. Chem. 542 (2003) 61.

[20] B. Bozzini, L. D’Urzo, V. Romanello, C. Mele, J. Electrochem. Soc. 153 (2006) C254.

[21] Z.D. Schultz, Z.V. Feng, M.E. Biggin, A. Gewirth, J. Electrochem. Soc. 153 (2006) C97.

[22] W.-P. Dow, H.-Sh. Huang, M.-Y. Yen, H.-H. Chen, J. Electrochem. Soc. 152 (2005) C77.

[23] G.A. Hope, R. Woods, J. Electrochem. Soc. 151 (2004) C550.

[24] B. Bozzini, C. Mele, L. D’Urzo, G. Giovannelli, S. Natali, J. Appl. Electrochem. 36 (2006) 789.

[25] M. Kang, A.A. Gewirth, J. Electrochem. Soc. 150 (2003) C426.

[26] J.P. Healy, D. Pletcher, M. Goodenough, J. Electroanal. Chem. 338 (1992) 155.

[27] J.J. Kelly, A.C. West, J. Electrochem. Soc. 145 (1998) 3472.

[28] V.D. Jovic, B.M. Jovic, J. Serb. Chem. Soc. 66 (2001) 935

[29] L. Bonou, M. Eyraud, R. Denoyel, Y. Massiani, Electrochim. Acta 47 (2002) 4139.

[30] Z.V. Feng, X. Li, A.A. Gewirth, J. Phys. Chem. B 107 (2003) 9415.

[31] J.P. Healy, D. Pletcher, M. Goodenough, J. Electroanal. Chem. 338 (1992) 167

[32] J.P. Healy, D. Pletcher, M. Goodenough, J. Electroanal. Chem. 338 (1992) 179

[33] T.P. Moffat, D. Wheeler, D. Josell, J. Electrochem. Soc. 151 (2004) C262.

[34] A.E. Bolzán, A.S.M.A. Haseeb, P.L. Schilardi, R.C.V. Piatti, R.C. Salvarezza, A.J. Arvia, J. Electroanal. Chem. 500 (2001) 533. 
[35] M.A. Pasquale, A.E. Bolzán, J.A. Guida, R.C.V. Piatti, A.J. Arvia, O.E. Piro, E.E. Castellano, Solid State Sci. 9 (2007) 862.

[36] W.-P. Dow, H.-S. Huang, J. Electrochem. Soc. 152 (2005) C67.

[37] J.G. Long, P.C. Searson, P.M. Vereecken, J. Electrochem. Soc. 153 (2006) C258.

[38] C. Gabrielli, P. Mocoteguy, H. Perrot, R. Wiart, J. Electroanal. Chem. 572 (2004) 367.

[39] C. Gabrielli, P. Mocoteguy, H. Perrot, D. Nieto-Sanz, A. Zdunek, Electrochim. Acta 51 (2006) 1462.

[40] Q. Wu, Ph.D. Thesis, University of New Hampshire, Durham, USA, 1998.

[41] L.M. Gassa, J.L. Lami, A.E. Bolzán, A.J. Arvia, J. Electroanal. Chem. 527 (2002) 71.

[42] R. de Levie, J. Electroanal. Chem. 281 (1990) 1.

[43] M. Keddam, H. Takenouti, Electrochim. Acta 33 (1988) 445

[44] E.E. Farndon, F.C. Walsh, S.A. Campbell, J. Appl. Electrochem. 25 (1995) 574.

[45] R. de Levie, in: P. Delahay, Ch.W. Tobias (Eds.), Advances in Electrochemistry and Electrochemical Engineering, vol. 6, J. Wiley, New York, 1967, p. 329.

[46] D.M. Kolb, in: H. Gerischer, G. Tobias (Eds.), Advances in Electrochemical Science and Engineering, vol. 11, J. Wiley, New York, 1978.

[47] R.R. Adzic, Israel J. Chem. 18 (1979) 166.

[48] D.A. Berg, D.S. Nadezdhim, R.G. Barradas, J. Electroanal. Chem. 355 (1993) 165

[49] A. Hernández Creus, R.M. Souto, S. González, M.M. Laz, R.C. Salvarezza, A.J. Arvia, Appl. Surf. Sci. 81 (1994) 387.

[50] A.J. Bard (Ed.), The Encyclopedia of the Electrochemistry of the Elements, vol. 2, Marcel Dekker, NY, 1974.
[51] S. Trasatti, EJ. Lust, in: R.E. White, J.O.M. Bockris, B.E. Conway (Eds.), Modern Aspects of Electrochemistry, 33, Plenum Press, New York, 1999.

[52] A. Lukomska, J. Sobkowski, J. Electroanal. Chem. 567 (2004) 95.

[53] E. Mattson, J.O.M. Bockris, Trans. Faraday Soc. 55 (1959) 1586.

[54] J.O.M. Bockris, M. Enyo, Trans. Faraday Soc. 58 (1962) 1187.

[55] O.R. Brown, H.R. Thirsk, Electrochim. Acta 10 (1965) 383.

[56] E. Budevski, G. Staikov, W.J. Lorenz, Electrochemical Phase Formation and Growth: An Introduction to the Initial Stages of Metal Deposition, VCH, New York, 1996.

[57] R. Winand, P. Van Ham, R. Colin, D. Milojevic, J. Electrochem. Soc. 144 (1997) 428.

[58] E. Chassaing, R. Wiart, Electrochim. Acta 17 (1984) 649.

[59] O.M. Magnusen, Chem. Rev. 102 (2002) 679.

[60] F. Oberholtzer, P.D. Barkey, Q. Wu, Phys. Rev. E 57 (1998) 6955.

[61] P.D. Barkey, F. Oberholtzer, Q. Wu, J. Electrochem. Soc. 145 (1998) 590

[62] Q. Wu, P.D. Barkey, J. Electrochem. Soc. 147 (2000) 1038.

[63] A. Frank, A.J. Bard, J. Electrochem. Soc. 150 (2003) C24.

[64] M.L. Walker, L.J. Richter, T. Moffat, J. Electrochem. Soc. 153 (2006) C557.

[65] M.A. Pasquale, S.L. Marchiano, G. Saracco, A.J. Arvia, J. Phys. Chem. B 109 (2005) 1089.

[66] C.R. Wilke, C.W. Tobias, M. Eisenberg, Chem. Eng. Progr. 49 (1953) 663.

[67] K.I. Popov, P.M. Živković, B.N. Grgur, Electrochim. Acta 52 (2007) 4696. 